\title{
Aerobic Training Prevents Heatstrokes in Calsequestrin-1 Knockout Mice by Reducing Oxidative Stress
}

\author{
Flávia Alessandra Guarnier $\mathbb{D}^{1,2,3}$ Antonio Michelucci, ${ }^{1,2}$ Matteo Serano, ${ }^{1}$ \\ Laura Pietrangelo, ${ }^{1,2}$ Claudia Pecorai, ${ }^{1,4}$ Simona Boncompagni $\mathbb{D}^{1,2}$ \\ and Feliciano Protasi $\mathbb{D}^{1,4}$ \\ ${ }^{1}$ Center for Research on Ageing and Translational Medicine (CeSI-MeT), University G. d'Annunzio, 66100 Chieti, Italy \\ ${ }^{2}$ Department of Neuroscience, Imaging, and Clinical Sciences (DNICS), University G. d'Annunzio, 66100 Chieti, Italy \\ ${ }^{3}$ Department of General Pathology, Londrina State University, 86057-970 Londrina, PR, Brazil \\ ${ }^{4}$ Department of Medicine and Aging Science (DMSI), University G. d'Annunzio, 66100 Chieti, Italy
}

Correspondence should be addressed to Flávia Alessandra Guarnier; faguarnier@yahoo.com.br

Received 24 November 2017; Revised 1 February 2018; Accepted 21 February 2018; Published 3 April 2018

Academic Editor: Yong Zhang

Copyright (c) 2018 Flávia Alessandra Guarnier et al. This is an open access article distributed under the Creative Commons Attribution License, which permits unrestricted use, distribution, and reproduction in any medium, provided the original work is properly cited.

Calsequestrin-1 knockout (CASQ1-null) mice suffer lethal episodes when exposed to strenuous exercise and environmental heat, crises known as exertional/environmental heatstroke (EHS). We previously demonstrated that administration of exogenous antioxidants ( $\mathrm{N}$-acetylcysteine and trolox) reduces CASQ1-null mortality during exposure to heat. As aerobic training is known to boost endogenous antioxidant protection, we subjected CASQ1-null mice to treadmill running for 2 months at $60 \%$ of their maximal speed for $1 \mathrm{~h}, 5$ times/week. When exposed to heat stress protocol $\left(41^{\circ} \mathrm{C} / 1 \mathrm{~h}\right)$, the mortality rate of CASQ1-null mice was significantly reduced compared to untrained animals ( $86 \%$ versus $16 \%$ ). Protection from heatstrokes was accompanied by a reduced increase in core temperature during the stress protocol and by an increased threshold of response to caffeine of isolated extensor digitorum longus muscles during in vitro contracture test. At cellular and molecular levels, aerobic training (i) improved mitochondrial function while reducing their damage and (ii) lowered calpain activity and lipid peroxidation in membranes isolated from sarcoplasmic reticulum and mitochondria. Based on this evidence, we hypothesize that the protective effect of aerobic training is essentially mediated by a reduction in oxidative stress during exposure of CASQ1-null mice to adverse environmental conditions.

\section{Introduction}

Hyperthermia is an abnormal rise in body temperature above the hypothalamic set point caused by excessive accumulation of external (environmental) or internal (metabolic) heat. When the core body temperature rises above $40^{\circ} \mathrm{C}$, hyperthermia may result in heatstroke, a life-threatening episode characterized by dysfunction of central nervous system and peripheral organs [1].

Malignant hyperthermia (MH), identified and described for the first time in 1960 [2], is an inherited pharmacogenetic disorder that manifests as a life-threatening hypermetabolic response to the administration of volatile anesthetics such as halothane or isofluorane $[2,3]$. The main clinical features of $\mathrm{MH}$ crises include uncontrolled muscle contracture, rupture of muscle fibers (i.e., rhabdomyolysis), increased circulating levels of creatine kinase (CK) and $\mathrm{K}^{+}$, and increased oxygen consumption [3]. Interestingly, hyperthermic crises known as exertional/environmental heatstroke (EHS), but virtually identical to anesthetic-induced $\mathrm{MH}$ episodes, have also been reported in humans exposed to elevated environmental temperatures or strenuous exercise performed in challenging conditions $[1,4-6]$.

Most of families (70-80\%) affected by MH susceptibility present mutations in the RYR1 gene [7], which encodes for a $2200 \mathrm{kDa}$ protein forming the sarcoplasmic reticulum (SR) $\mathrm{Ca}^{2+}$-release channel of skeletal muscle, the ryanodine receptor type-1 (RyR1) [8, 9]. An association between RYR1 
variants and exertional- or heat-induced rhabdomyolysis and sudden death has been reported [10-13]. The correlation between $\mathrm{MH}$ and EHS is also supported by evidence collected in animal models: (a) in porcine stress syndrome (PSS), swine carrying a point mutation in RYR1 trigger $\mathrm{MH}$ episodes in response to halothane administration but also following exposure to either heat or emotional/ physical stress [14, 15]; (b) knock-in mice carrying gainof-function point mutations in RYR1 linked to $\mathrm{MH}$ in humans exhibit heat- and anesthetic-induced $\mathrm{MH}$ episodes $[16,17]$. In addition, we discovered that male mice lacking calsequestrin-1 (CASQ1-null), the main $\mathrm{Ca}^{2+}$-binding protein located in the lumen of SR terminal cisternae that modulates RyR1 opening probability [18-20], exhibit lethal hyperthermic episodes when exposed to anesthetics, heat, and strenuous exercise [18, 21-23].

The molecular mechanisms underlying rhabdomyolysis of skeletal muscle fibers during $\mathrm{MH} / \mathrm{EHS}$ crises appear to be complex cascade of events revolving around an increased leak of $\mathrm{Ca}^{2+}$ from the mutated RyR1 [24-28] and an excessive production of reactive oxygen/nitrogen species (ROS/RNS) [24]. Michelucci et al. [23] demonstrated that administration of antioxidants ( $N$-acetylcysteine and trolox) protects CASQ1-null mice from anesthetic- and heat-induced lethal crises by reducing mitochondrial production of superoxide anion and global oxidative stress.

Oxidative stress levels in a cell are the net result of production and removal of oxidative species since the early 80 s, it has been demonstrated that aerobic training promotes mitochondrial biogenesis in skeletal muscle while boosting endogenous antioxidant levels [29]. It seems that, although free radical production increases during exercise [30], their rise may act as a signal leading to both upregulation and increased activity of antioxidant enzymes [31-33].

In the present study, we hypothesized that aerobic training, by boosting antioxidant defenses [31-33], could reduce mortality of CASQ1-null mice during hyperthermic crisis. The results collected in this study indicate that training effectively protects CASQ1-null mice from EHS, an effect essentially mediated by a significant reduction in oxidative stress.

\section{Materials and Methods}

2.1. CASQ1-Null Male Mice. CASQ1-null mice were generated as previously described [27]. All animals used in this study were males, as this gender is more susceptible to $\mathrm{MH}$ / EHS-like crises when exposed to halothane and heat [22]. Mice were housed in microisolator cages at $20^{\circ} \mathrm{C}$ in a $12 \mathrm{~h}$ light/dark cycle, provided free access to water and food. Age-matched C57BL/6 (WT) mice were used as controls. All experiments were conducted according to the Directive of the European Union 2010/63/UE and were approved by the Italian Ministry of Health (1199/2015-PR).

\subsection{In Vivo Experiments}

2.2.1. Incremental Test. This protocol consisted of a single session of exercise on a treadmill with no incline, according to the protocol described by Cunha et al. [34] and Gladden and Hogan [35], performed at room temperature of 20 $\pm 2^{\circ} \mathrm{C}$. A mild electrical stimulus $(0.5 \mathrm{~mA})$ was applied to mice that stepped off the treadmill to keep them exercising. The test started with a warm-up of $10 \mathrm{~min}$ at a speed of $6 \mathrm{~m} / \mathrm{min}$. The speed of the treadmill was then increased by $3 \mathrm{~m} / \mathrm{min}$ (from 6 to $39 \mathrm{~m} / \mathrm{min}$ ) every $3 \mathrm{~min}$ until exhaustion, defined as the time when the mice were no longer able to maintain regular gait. Workloads corresponding to 85 and $60 \%$ of peak workload were determined for each mouse.

\subsubsection{Constant Load Test and Lactate Measurements. This} protocol consisted of a warm-up period of $10 \mathrm{~min}$ at $6 \mathrm{~m} /$ min followed by a $28 \mathrm{~min}$ constant load running on a treadmill with no incline (at $85 \%$ of maximal speed reached in the incremental test) [33], performed at room temperature of $20 \pm 2^{\circ} \mathrm{C}$. Blood samples $(\sim 50 \mu \mathrm{L})$ were collected from the tail vein while mice were kept running, every $7 \mathrm{~min}$. Blood was then transferred to $1.5 \mathrm{~mL}$ microtubes, centrifuged at $3000 \times \mathrm{g}$ for $15 \mathrm{~min}$ at $4^{\circ} \mathrm{C}$ for plasma separation, and stored in $200 \mu \mathrm{L}$ microtubes at $-20^{\circ} \mathrm{C}$. The lactate concentration in the blood was analyzed in plasma using a colorimetric enzymatic assay kit (Lactate Assay Kit II; Sigma-Aldrich ${ }^{\circledR}$, St. Louis, MO, USA), following the manufacturer's instructions. The lactate concentration in the colorimetric reaction was measured spectrophotometrically at $450 \mathrm{~nm}$ (Spectra MAX 190; Molecular Devices, Sunnyvale, CA, USA) and expressed as $\mathrm{mmol}$ of lactate/L.

2.2.3. Grip Strength Test. The strength developed by mice during instinctive grasp was measured as previously described [23, 36, 37]. Briefly, mice were held by the tail and allowed to grasp a metal grating connected to a Shimpo Fgy 0.5X transducer (Metrotec Group, Spain). Once the mouse had firmly grasped the grating, a steady and gentle pull was exerted on the tail. Measurements of the peak force generated by each mouse using forelimbs were repeated three times with appropriate intervals (about $30 \mathrm{~s}$ ) to avoid fatigue. Average peak force values were then normalized to the total body mass.

2.2.4. Aerobic Training Protocol. WT $(n=7)$ and CASQ1null $(n=21)$ mice were enrolled in the study at 2 months of age after weight and grip strength were measured. Each mouse was then (a) accustomed for 5 days to treadmill running (Columbus Instruments, Columbus, OH, USA), (b) subjected to the incremental test (see above), and (c) randomly assigned to the CASQ1-null training $(n=7)$ or to the control groups $(n=14)$. The training group of CASQ1null mice was subjected to aerobic training $[33,34]$ on the treadmill at $60 \%$ of their individual maximal speed reached during the incremental test. After 4 weeks, trained CASQ1null mice performed a new incremental test to readjust the training load and guarantee the $60 \%$ of workload in the following 4 weeks. At the end of 8 weeks of training, body weight and grip strength were reassessed for all mice (WT and CASQ1-null control and trained), which were also reevaluated with the incremental test. After 2 days of rest, all animals additionally performed a constant load test (see 


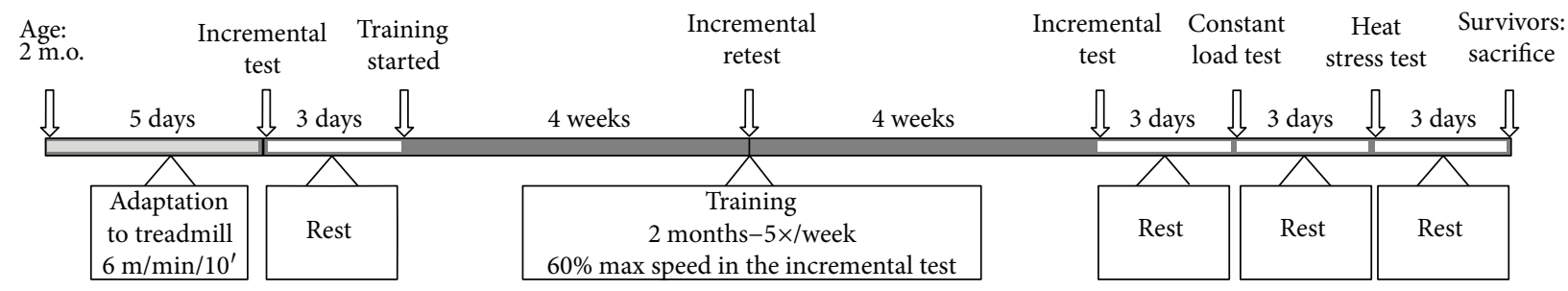

FIGURE 1: Schematic view of the experimental protocol. Two months old CASQ1-null male mice were randomly selected to perform 2 months of aerobic training. Control WT and untrained (control) CASQ1-null mice were always subjected to identical procedures, without the aerobic training. m.o.: months old.

above) with blood collection, to measure the lactate accumulation/removal ratio. A detailed overview of experimental protocol is shown in Figure 1.

2.2.5. Heat Stress Protocol and Core Temperature Recording. Three days after the constant load test (see above), all mice were subjected to a heat stress protocol. Animals were placed in an environmental chamber in which temperature was maintained at $41^{\circ} \mathrm{C}, 1 \mathrm{~h}$ [21]. During exposure to heat, core body temperature was measured using a rectal thermometer taped to the tail of the animals and recorded every $5 \mathrm{~min}$ throughout the duration of heat challenge. Breathing and spasmodic contractions were visually monitored, while muscle rigidity was manually confirmed by limb resistance immediately after animal death. Surviving animals were returned to normal housing conditions and monitored for $24 \mathrm{~h}$ to assess possible delayed deaths. After 3 days, the mice that survived from the heat stress protocol were sacrificed, and muscle samples collected and processed for further analysis.

\subsection{Ex Vivo and In Vitro Experiments}

2.3.1. In Vitro Contracture Test (IVCT) in (EDL) Muscles. Intact EDL muscles were dissected from hind limbs of mice, placed in a dish containing Krebs-Henseleit solution, and pinned and tied with fine silk sutures at each end. Muscles were then mounted vertically between two platinum electrodes immersed in an organ chamber filled with KrebsHenseleit solution and attached to a servomotor and force transducer (model 1200A; Aurora Scientific, Aurora, ON, Canada). Before starting the experimental protocol, stimulation level and optimal muscle length $\left(L_{0}\right)$ were determined using a series of $80 \mathrm{~Hz}$ train stimulus in order to adjust the muscle to the length that generated maximal force $\left(F_{0}\right)$. During the experiments, temperature was kept constant at $25^{\circ} \mathrm{C}$. To determine caffeine sensitivity of resting tension, EDL muscles were subjected to an in vitro contracture test (IVCT) as previously described [23]. Briefly, isolated EDL muscles were continuously stimulated at $0.2 \mathrm{~Hz}$ at $23-25^{\circ} \mathrm{C}$, caffeine concentration in the bath was changed every 3 minutes (no wash between applications) as follows: 2, 4, 6, 8, 10, 14, 18, and $22 \mathrm{mM}$. Muscle basal tension was measured at the end of each step of caffeine application and reported both as specific and relative force. Specific force was calculated by normalizing the absolute force to the cross-sectional area of the muscle.
2.3.2. Preparation of Total Homogenates and Isolation of Mitochondria and SR Membranes. Total homogenates were prepared by placing muscles tibialis anterior (TA) and gastrocnemius on ice in an Ultra-Turrax homogenizer $(2 \times 30 \mathrm{~s}$ at $14,500 \mathrm{rpm}$ ) containing $50 \mathrm{mg} / \mathrm{mL}$ of tissue in $10 \mathrm{mM}$ $\mathrm{KH}_{2} \mathrm{PO}_{4} / \mathrm{K}_{2} \mathrm{HPO}_{4}$ buffer and $120 \mathrm{mM} \mathrm{KCl}$ at $\mathrm{pH} 7.4$ [38]. Total homogenate preparations were used for assessment of total diene conjugates production, protein carbonylation, and calpain activity assays (see below).

Mitochondria and SR membranes were isolated from gastrocnemius to assay-specific organelle lipid peroxidation. Samples were placed in an Ultra-Turrax homogenizer $(2 \times 30 \mathrm{~s}$ at $14,500 \mathrm{rpm})$ in $5 \mathrm{vol}$ of $30 \mathrm{mM} \mathrm{KH} \mathrm{PO}_{4}, 5 \mathrm{mM}$ EDTA, 3.0 M sucrose, $0.5 \mathrm{mM}$ dithiothreitol, $0.3 \mathrm{mM}$ phenylsulfonyl fluoride, and $1 \%(\mathrm{v} / \mathrm{v}), 1 \mu \mathrm{M}$ leupeptin, $1 \mu \mathrm{M}$ pepstatin (pH 6.8). All steps for isolation were performed at $4^{\circ} \mathrm{C}$. Mitochondrial fraction was prepared from the total homogenates by differential centrifugation as previously described [39]. The supernatant from a first homogenate centrifugation ( $1000 \times \mathrm{g}$ for $10 \mathrm{~min}$ ) was centrifuged at $14,000 \times \mathrm{g}$ for $35 \mathrm{~min}$. The pellet was then suspended in $30 \mathrm{mM}$ imidazole, $60 \mathrm{mM}$ $\mathrm{KCl}$, and $2 \mathrm{mM} \mathrm{MgCl}_{2}$ (pH 7.0) and stored at $-80^{\circ} \mathrm{C}$ until use. This resuspension was then used to assay cytochrome $c$ oxidase activity and lipid peroxidation in mitochondrial membranes. Microsomes vesicles were prepared by isoelectric precipitation from the supernatant of mitochondrial isolation as previously described [40, 41]. Sodium acetate $(1 \mathrm{mM})$ was added to the samples until the $\mathrm{pH}$ was 4.0 and then centrifuged at $10,000 \times \mathrm{g}$ for $10 \mathrm{~min}$. The supernatants were discharged, and pellets were resuspended in the same volume that was initially used, of $\mathrm{KCl} 1.15 \%$ glycerol $(4: 1 \mathrm{v} / \mathrm{v})$. The pellets were mechanically broken using a vortex and then centrifuged again in $10,000 \times \mathrm{g}$ for $10 \mathrm{~min}$. The final pellet was resuspended in $100 \mathrm{mM} \mathrm{KH}_{2} \mathrm{PO}_{4}$ and glycerol $(4: 1 \mathrm{v} / \mathrm{v})$, mixed using a vortex, and stored in microtubes at $-80^{\circ} \mathrm{C}$. For $\mathrm{Ca}^{2+}$-dependent ATPase activity, the pellets were resuspended in $3 \%$ polyethylene glycol, $5 \mathrm{mM}$ azide, $80 \mathrm{mM}$ $\mathrm{KCl}$, and $0.1 \mathrm{mM}$ ouabain ( $\mathrm{pH} 7.5$ ). Total proteins were quantified by the method of Bradford [42], using bovine serum as a standard.

2.3.3. Determination of $\mathrm{Ca}^{2+}$ ATPase Activity. Activity of sarco/endoplasmic $\mathrm{Ca}^{2+}$ ATPase (SERCA), the main SR $\mathrm{Ca}^{2+}$ pump of skeletal muscle, was estimated in SR isolated membranes from gastrocnemius by using a colorimetric assay that quantifies the amount of inorganic phosphate $\left(\mathrm{P}_{\mathrm{i}}\right)$ that complexes with ammonium molybdate 
and malachite green following release from SERCAmediated ATP hydrolysis [43, 44]. Briefly, the reagent to quantify $\mathrm{P}_{\mathrm{i}}$ was prepared by mixing 1 vol of $10 \%(\mathrm{w} / \mathrm{v})$ ammonium molybdate in $4 \mathrm{M} \mathrm{HCl}$ with 3 vol $0.2 \%(\mathrm{w} / \mathrm{v})$ malachite green in $4 \mathrm{M} \mathrm{HCl}$. The reaction medium, composed by $2 \mathrm{mM}$ EDTA, $10 \mathrm{mM} \mathrm{CaCl}, 2 \mathrm{mM} \mathrm{MgCl}_{2}$, and $2 \mathrm{mM}$ ATP, was mixed to malachite green/ammonium molybdate dye reagent, and then the reaction was started with the addition of $300 \mu \mathrm{g}$ protein $/ \mathrm{mL}$ of membranes resuspension. When $\mathrm{P}_{\mathrm{i}}$ was complexed with ammonium molybdate and malachite green in $4 \mathrm{M} \mathrm{HCl}$, it creates a green color which was quantified by reading the absorbance spectrophotometrically at $660 \mathrm{~nm}$ and compared to a standard curve of known $\mathrm{P}_{\mathrm{i}}$ concentrations (0-15 nmols of $\mathrm{PO}_{4}{ }^{-2}$ from $\left.\mathrm{NaPO}_{4}\right)$. The color formation was monitored for $5 \mathrm{~min}$, the $\mathrm{P}_{\mathrm{i}}$ concentration at every minute was calculated using a standard curve, and the differences are considered the activity of $\mathrm{Ca}^{2+}$ ATPase pump [44]. All the reactions were repeated in the presence of thapsigargin $(100 \mathrm{nM})$, an inhibitor of the SERCA family of $\mathrm{Ca}^{2+}$ pumps [45], to differentiate SERCA activity from any other ATP-dependent activity that could interfere with the measurement.

2.3.4. Determination of Calpain Activity. The activity of calpain $[46,47]$ was measured in total homogenates from gastrocnemius muscle, by a chemiluminescence assay using a calpain protease assay kit (Calpain-Glo Protease Assay ${ }^{\circledR}$; Promega, Madison, WI, USA). The assay provides a proluminescent calpain substrate, in a buffer system optimized for calpain and luciferase activities. During the assay, calpain cleavage of the substrate generates a glow-type luminescent signal produced by the luciferase reaction. In this homogeneous, coupled-enzyme format, the signal is proportional to the amount of calpain activity present in the sample [48]. Muscle homogenates were prepared as described above, diluted to a concentration of $6.25 \mathrm{mg} / \mathrm{mL}$ in $10 \mathrm{mM} \mathrm{KH}_{2} \mathrm{PO}_{4}$ buffer, $\mathrm{pH} 7.4$ in $0.9 \% \mathrm{NaCl}$, and finally processed according to the manufacturer's instructions. Results were expressed as calpain activity/mg of muscle tissue.

2.3.5. Preparation of Samples for Electron Microscopy (EM). EDL muscles were dissected from sacrificed animals, pinned on a Sylgard dish, fixed at room temperature with $3.5 \%$ glutaraldehyde in $0.1 \mathrm{M}$ sodium cacodylate $(\mathrm{NaCaCo})$ buffer ( $\mathrm{pH} 7.2$ ), and then stored in the fixative at $4^{\circ} \mathrm{C}$. Small bundles of fixed tissue were then postfixed, embedded, stained en bloc, and sectioned for EM as described previously [49]. Ultrathin sections $(\sim 50 \mathrm{~nm})$ were then cut in a Leica Ultracut $\mathrm{R}$ microtome (Leica Microsystem, Austria) using a Diatome diamond knife (Diatome Ltd. CH-2501 Biel, Switzerland). Sections were examined at $60 \mathrm{kV}$ (after double staining with uranyl acetate and lead citrate) with a FP 505 Morgagni Series 268D electron microscope (FEI Company, Brno, Czech Republic), equipped with a Megaview III digital camera (Munster, Germany) and Soft Imaging System (Munster, Germany).

2.3.6. Quantitative EM Analysis of Mitochondrial Volume and Damage. (A) Mitochondrial volume was determined using the well-established stereology point-counting technique $[50,51]$ in EM micrographs collected from transverse sections of samples at $8900 \times$ magnification. Briefly, after superimposing an orthogonal array of dots at a spacing of $0.20 \mu \mathrm{m}$ to the electron micrographs, the ratio between numbers of dots falling within mitochondrial profiles and total number of dots covering the whole image was used to calculate the relative fiber volume occupied by mitochondria. (B) In the same set of micrographs, the number of severely damaged mitochondria was evaluated and reported as percentage of the total number. Mitochondria with one of the following ultrastructural alterations were classified as severely damaged: (a) presenting disruption of the external membrane, (b) presence of internal vacuolization and/or disrupted internal cristae, and (c) containing myelin figures.

2.3.7. Cytochrome c Oxidase Activity. Cytochrome $c$ oxidase activity was measured in isolated mitochondria from gastrocnemius muscles, by a colorimetric assay kit (Cytochrome $c$ Oxidase Assay Kit; Sigma-Aldrich, St. Louis, MO, USA) based on the observation of the decrease in absorbance at $550 \mathrm{~nm}$ of ferrocytochrome $c$ caused by its oxidation to ferricytochrome $c$ by cytochrome $c$ oxidase [52]. All samples used in the assay had the same amount of protein ( $300 \mu \mathrm{g}$ protein/ $\mathrm{mL}$ ), and the results were expressed as cytochrome $c$ oxidase activity $\left(\mathrm{U} / \mathrm{mL} \times 10^{-3}\right)$.

2.3.8. Oxidative Stress Measurements. Protein carbonyl group formation is a classic and immediate biomarker of oxidative modification to proteins $[53,54]$. Here, carbonyl protein content was measured with a modified version of a protocol previously described [53]. Briefly, TA (50 mg/mL) was homogenized in $50 \mathrm{mM}$ of phosphate buffer, $1 \mathrm{mM}$ ethylenediaminetetraacetic acid, pH 7.4. Samples were then centrifuged at $600 \times \mathrm{g}$ for $10 \mathrm{~min}$ at $4^{\circ} \mathrm{C}$. A volume of $200 \mu \mathrm{L}$ of 2,4-dinitrophenylhydrazine (DNPH) was added to $200 \mu \mathrm{L}$ of supernatant and incubated at room temperature. After $30 \mathrm{~min}$ of incubation, $100 \%$ trichloroacetic acid (TCA) was added and samples were placed on ice for $5 \mathrm{~min}$ and then spinned at maximal speed for 2 min. Supernatants were discarded, while pellets were washed in cold acetone and placed at $-20^{\circ} \mathrm{C}$ for $5 \mathrm{~min}$. Then, acetone was carefully removed, and pellets were resuspended in $0.5 \mathrm{~mL} 6 \mathrm{M}$ guanidine hydrochloride to be spectrophotometrically read at $375 \mathrm{~nm}$. To calculate the protein carbonyl content, the following formula was used: $\quad C=[(\mathrm{OD} 375 \mathrm{~nm}) / 6.364 \times 100] \mathrm{nmol} /$ well, where 6.364 is the extinction coefficient using the enclosed 96 -well plates in $\mathrm{mM}\left(=22 \mathrm{mM}^{-1} \mathrm{~cm}^{-1} \times 0.2893 \mathrm{~cm}\right.$ path length in well). Results were expressed as nmol carbonyl/mg of total protein, which were quantified in each sample at $280 \mathrm{~nm}$.

Oxidation of fatty acids forms conjugated dienes that absorb UV light at 230 to $235 \mathrm{~nm}$. Measurement of dienes is a useful index of peroxidation in pure lipids or isolated lipoproteins and has the advantage that it measures early stages in peroxidation [55]. Muscle homogenate and SR vesicles were dispensed in concentration of $20 \mu \mathrm{g} / \mathrm{mL}$ protein in solution with $10 \mathrm{mM}$ phosphate buffer containing 1\% Lubrol [56]. The absorption spectrum was then recorded. The rate of conjugated diene formation was estimated according to the 
TABLE 1: Body weight and functional output of mice before and after training.

\begin{tabular}{|c|c|c|c|c|c|}
\hline & \multicolumn{2}{|c|}{$\begin{array}{c}\text { Pretraining } \\
(2 \text { months of age })\end{array}$} & \multicolumn{3}{|c|}{$\begin{array}{c}\text { Posttraining } \\
\text { (4 months of age) }\end{array}$} \\
\hline & $\begin{array}{c}\text { WT } \\
(n=7)\end{array}$ & $\begin{array}{l}\text { CASQ1-null } \\
\quad(n=21)\end{array}$ & $\begin{array}{l}\text { WT } \\
(n=7)\end{array}$ & $\begin{array}{l}\text { CASQ1-null } \\
\quad(n=14)\end{array}$ & $\begin{array}{c}\text { Trained } \\
\text { CASQ1-null } \\
(n=7)\end{array}$ \\
\hline Body weight (g) & $24.6 \pm 2.9$ & $23.6 \pm 2.5$ & $29.9 \pm 2.8$ & $27.0 \pm 2.9$ & $25.7 \pm 3.0$ \\
\hline Grip strength normalized (peak force g/g weight) & $9.7 \pm 1.5$ & $3.9 \pm 1.6^{*}$ & $7.9 \pm 1.7$ & $3.0 \pm 0.8^{\dagger}$ & $4.8 \pm 1.1^{\#}$ \\
\hline Max. speed in the incremental test (m/min) & $24.8 \pm 3.1$ & $27.8 \pm 3.0^{*}$ & $24.0 \pm 2.1$ & $28.1 \pm 2.7^{\dagger}$ & $32.5 \pm 3.9^{\#}$ \\
\hline
\end{tabular}

Data are shown as mean \pm SD. ${ }^{*} p<0.05$ compared to age-matched WT, as evaluated by two-tailed unpaired Student's $t$-test for the $95 \%$ confidence intervals; ${ }^{\dagger} p<0.05$ when compared to WT at 4 months, and ${ }^{\#} p<0.05$ compared to untrained CASQ1-null, as evaluated by one-way ANOVA followed by Tukey's post hoc test. All groups were tested for normal distribution by Kolmogorov-Smirnov test and outlier detection by Grubb's test.

lipid oxidation index, $A_{233 \mathrm{~nm}} / \mathrm{A}_{215 \mathrm{~nm}}$, which provides a sensitive method for determination of lipid peroxidation [57].

2.4. Statistical Analysis. The statistical analysis is reported in the legend of each figure. Mean \pm SD was used when variability representative values are needed (higher number of samples/animals), while mean \pm SEM was used to represent precision of a measurement (lower number of samples/ animals).

\section{Results}

3.1. Aerobic Training Increased Functional Output and Aerobic Capacity of CASQ1-Null Mice. Before the 2 months training protocol, and two days after the last training session, body weight and grip strength were evaluated in each mouse (Table 1). Body weight between WT and CASQ1-null mice, although slightly lower in the latter at both 2 and 4 months of age, was not significantly different. Significant differences were observed for the functional output, as the grip strength test revealed that untrained CASQ1-null mice were about $60 \%$ weaker than age-matched WT at both 2 and 4 months of age. On the other hand, the maximum speed reached during the incremental test was surprisingly higher in CASQ1null mice: this last result is likely due to the increased number and volume of mitochondria in CASQ1-null muscles (see below; see also [27]). Two months of aerobic training (2 to 4 months of age; see Figure 1), while did not change the average body weight of CASQ1-null mice, significantly improved both functional parameters: (a) the grip strength output normalized by weight increased from $3.0 \pm 0.8 \mathrm{~g} / \mathrm{g}$ of body weight in untrained CASQ1-null to $4.8 \pm 1.1 \mathrm{~g} / \mathrm{g}$ of body weight in trained CASQ1-null and (b) the maximum speed reached during the incremental test was slightly higher in trained than in untrained CASQ1-null mice, respectively, $32.5 \pm 3.9$ versus $28.1 \pm 2.7 \mathrm{~m} / \mathrm{min}$.

As lactate accumulation/removal ratio is considered a good marker of aerobic capacity $[58,59]$, we subjected all mice at 4 months of age to a 28 -minute constant load test (at $85 \%$ of the maximal speed reached during the incremental test) and measured the lactate accumulation in the bloodstream every 7 minutes (Figure 2(a)). WT mice displayed a typical lactate accumulation curve, increasing from baseline $(0.09 \pm 0.30 \mathrm{mmol} / \mathrm{L})$ to a peak at the 14 th minute of 2.87 $\pm 0.90 \mathrm{mmol} / \mathrm{L}$, followed by a plateau. On the other hand, the lactate levels in the bloodstream in untrained CASQ1null mice $(1.11 \pm 0.46$ at baseline) reached a peak of 3.38 $\pm 1.10 \mathrm{mmol} / \mathrm{L}$ at the 14 th minute, but then declined in the second part of the experiment. This decay was even greater in trained CASQ1-null mice, with a peak of 2.10 $\pm 0.73 \mathrm{mmol} / \mathrm{L}$ at 7 th minute followed by a constant decline. Indeed, the blood lactate concentration at the end of the constant load test (28th minute; dashed line in Figure 2(a)) exhibited a reduction compared to WT mice of, respectively, $\sim 39 \%$ and $\sim 70 \%$ in untrained and trained CASQ1-null animals (Figure 2(b)).

\subsection{Aerobic Training Decreased Mitochondrial Damage and} Improved Mitochondrial Function in CASQ1-Null Mice. In EDL fibers of WT mice, mitochondria are usually positioned at the I band in proximity of $Z$ lines (Figures 3(a)-3(c) black arrows; see [60]). Healthy mitochondria usually exhibit an electron dense dark matrix (inset in Figure 3(a)), while when damaged, they would appear swollen and with a clear matrix [61]. A first qualitative assessment suggested that damaged mitochondria were more numerous in untrained CASQ1null than in WT mice (Figure 3(b), empty arrows), but again rare in trained CASQ1-null mice (Figure 3(c)). The visual observations were supported by the quantitative analysis: (i) the relative volume occupied by mitochondria and (ii) the percentage of mitochondria presenting structural alterations were significantly higher in untrained CASQ1-null (6.6 $\pm 0.6 \%$ and $21.6 \pm 3.8 \%)$ than in WT mice $(3.9 \pm 0.4 \%$ and $5.8 \pm 1.4 \%$ ) (Figures $3(\mathrm{~d})$ and $3(\mathrm{e})$ ). On the other hand, in trained CASQ1-null mice, while the relative volume occupied by mitochondria did not change significantly compared to untrained CASQ1-null mice (6.2 $\pm 0.6 \%$ versus $6.6 \pm 0.6 \%)$, the percentage of damaged mitochondria was significantly reduced to a value close to that observed in WT muscles $(8.6 \pm 1.4 \%$ versus $5.8 \pm 1.4 \%$; see above) (Figures $3(\mathrm{~d})$ and $3(\mathrm{e})$ ). The structural improvement of mitochondrial structure would also suggest improved functional properties of mitochondria. Indeed, when we measured cytochrome $c$ oxidase activity, we found that it was decreased in untrained CASQ1-null mice $(0.05 \pm 0.006 \mathrm{U} / \mathrm{mL})$ compared to WT $(0.076 \pm 0.01 \mathrm{U} / \mathrm{mL})$, but rescued to values closer to those of WT following training $(0.067 \pm 0.006 \mathrm{U} / \mathrm{mL}$; Figure $3(\mathrm{f}))$. The data collected in the analysis of mitochondria could have 


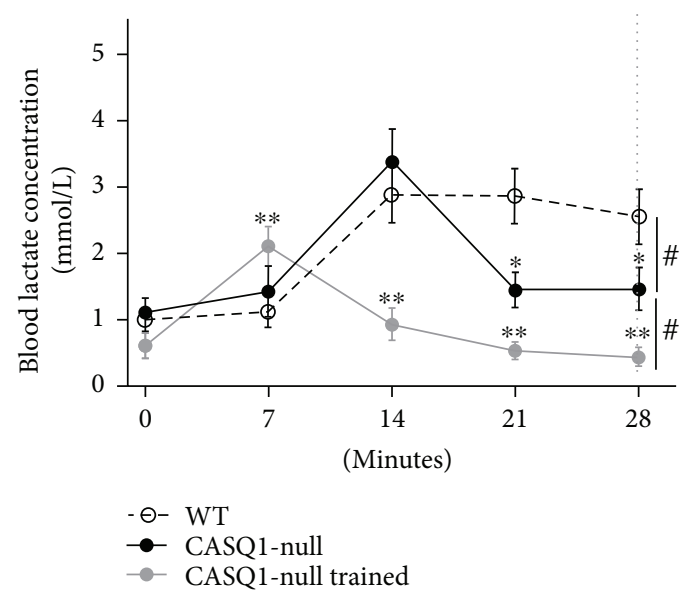

(a)

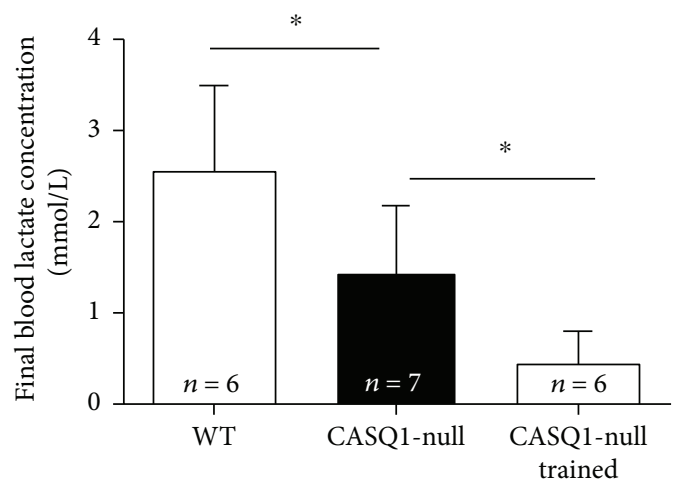

(b)

FIgURe 2: Accumulation of lactate in the bloodstream during constant load test. (a) Lactate accumulation in the blood during a 28-minute constant load test (at $85 \%$ of maximal speed reached during the incremental test). The vertical dashed line represents the time point in which final blood lactate concentration (plotted in panel (b)) was evaluated. ${ }^{*} p<0.05$, as evaluated by two-way ANOVA (differences among paired curves); ${ }^{*} p<0.05$, CASQ1-null versus WT, and ${ }^{* *} p<0.05$, CASQ1-null versus CASQ1-null trained, as evaluated by Bonferroni's post hoc test (indicating differences among the same time point). (b) Average blood lactate concentration at the end of incremental test (28th minute; dashed line in panel (a)). Data are given as mean $\pm \mathrm{SD} ;{ }^{*} p<0.05$, as evaluated by one-way ANOVA followed by Tukey's post hoc test. $n=$ number of mice.

implications for (i) the improved functional output (Table 1) and (ii) the higher capability of trained CASQ1-null mice to remove lactate (Figure 2).

3.3. Aerobic Training Protects Male CASQ1-Null Mice from Heat-Induced Sudden Death by Reducing Hyperthermia. Three days after the constant load test, all mice were subjected to a heat challenge in an environmental chamber $\left(41^{\circ} \mathrm{C}\right.$ for $\left.1 \mathrm{~h}\right)$. Consistent with previous publications [21, 23], mortality rate during the heat stress protocol was significantly higher in CASQ1-null than in WT mice: $86 \%$ versus $18 \%$, respectively (Figures 4(a) and 4(b)). Though, the mortality rate of CASQ1-null mice was reduced to only $16 \%$ after two months of aerobic training (Figures 4(a) and 4(b)). As a typical $\mathrm{MH}$ crisis is characterized by an abnormal rise in body temperature, namely, hyperthermia [1], we also monitored the core temperature throughout the entire duration of the heat challenge. Whereas core temperature raised in all animals (including WT) during the experiment, this increase was significantly greater in untrained CASQ1-null mice than in the other two groups of animals tested (Figure 4(c)). Specifically, the temperature calculated at 45th minute of the protocol, that is the average time-to-onset of hyperthermic crises in CASQ1null mice $[18,23]$, was (i) on average $1.85^{\circ} \mathrm{C}$ higher in untrained CASQ1-null than in WT mice (Figure 4(d)) and (ii) on average $1.79^{\circ} \mathrm{C}$ lower in trained CASQ1-null than in untrained CASQ1-null mice, close to the temperature observed in WT animals (Figure 4(d)).

3.4. Aerobic Training Normalizes IVCT in CASQ1-Null EDL Muscles. Intact EDL muscles were dissected from all mice and subjected to IVCT, the gold standard for the diagnosis of MH susceptibility in humans $[62,63]$. Basal force of EDL muscles was measured during exposure to increasing concentrations of caffeine, a potent agonist of RyR1 that triggers release of $\mathrm{Ca}^{2+}$ from the SR. Force is displayed in Figures 5(a) and 5(b) as absolute and relative basal tension, respectively. While no differences in the specific basal tension were recorded among the three groups of animals in the absence of caffeine $\left(7.9 \pm 0.4 \mathrm{mN} / \mathrm{mm}^{2}, 7.8 \pm 0.2 \mathrm{mN} / \mathrm{mm}^{2}\right.$, and 8.0 $\pm 0.4 \mathrm{mN} / \mathrm{mm}^{2}$ for WT untrained and trained CASQ1-null mice, resp.), when exposed to the IVCT protocol, EDL muscles from untrained CASQ1-null mice exhibited a greater caffeine sensitivity compared to those observed from WT (Figure 5). Specifically, EDL muscles from untrained CASQ1-null mice started to develop tension already at $10 \mathrm{mM}$ and reached a final tension value of $12.5 \pm 0.4 \mathrm{mN} /$ $\mathrm{mm}^{2}$ at $22 \mathrm{mM}$ of caffeine. Two months of aerobic training normalized the responsiveness to caffeine of CASQ1-null EDL muscles to values similar to that observed in WT: at $22 \mathrm{mM}$ of caffeine, the specific basal tension reached by EDL muscles from WT and trained CASQ1-null mice was $9.7 \pm 0.3 \mathrm{mN} / \mathrm{mm}^{2}$ and $10.4 \pm 0.3 \mathrm{mN} / \mathrm{mm}^{2}$, respectively (Figure 5(a)). In Figure 5(b), force is displayed as relative basal tension normalized to control conditions (no caffeine) during the exposure to increasing concentrations of caffeine.

3.5. Calpain Activity Was Reduced in Muscles of Trained CASQ1-Null Mice. Cytosolic $\mathrm{Ca}^{2+}$ levels have been shown to be slightly elevated in CASQ1-null fibers $[18,21,23]$ and may lead to an increased need of $\mathrm{Ca}^{2+}$ removal from the cytosol [37, 64]. For this reason, we measured SERCA activity in microsomal membranes of gastrocnemius muscles, estimated as production of $\mathrm{P}_{\mathrm{i}}$ in the presence of ATP (Figure 6(a)). Our results showed that the rate of $P_{i}$ generated in untrained CASQ1-null samples was significantly 


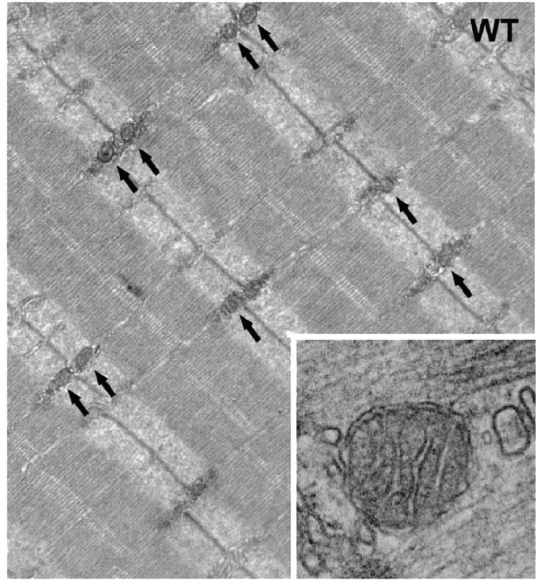

(a)

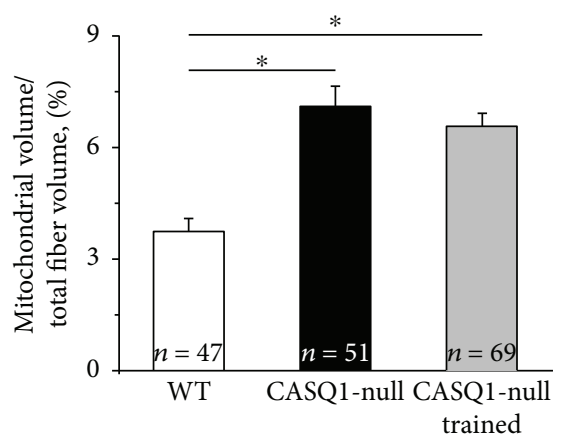

(d)

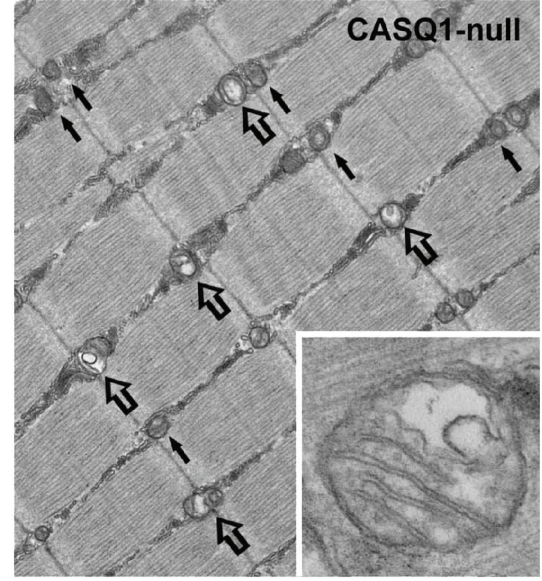

(b)

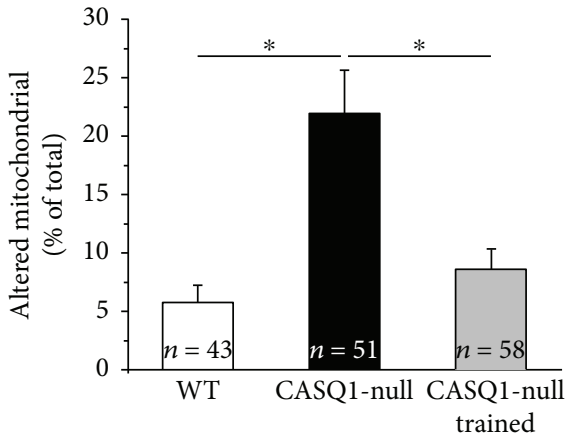

(e)

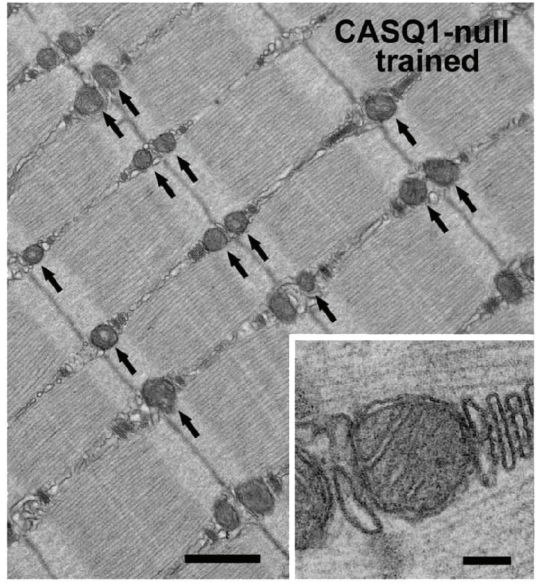

(c)

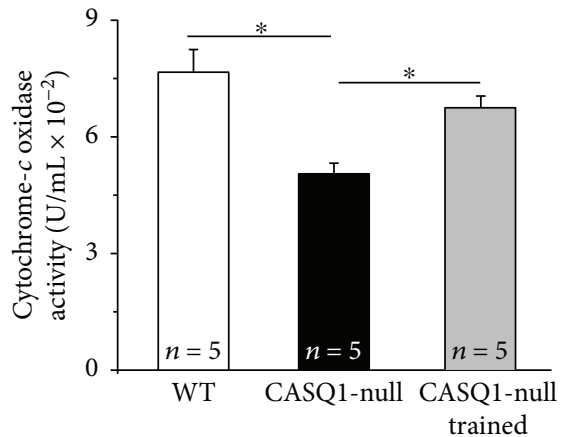

(f)

FIGURE 3: Structural and quantitative analysis of mitochondria. $(a-c)$ Representative electron micrographs (longitudinal sections) of EDL fibers where small black arrows point to healthy mitochondria (see enlargements in (a) and (c)), while empty arrows point to damaged mitochondria (see enlargement in (b)). Scale bars in $(\mathrm{a}-\mathrm{c}), 1 \mu \mathrm{m}$; insets, $0.1 \mu \mathrm{m}$. (d) Quantitative analysis of the relative fiber volume occupied by mitochondria. (e) Quantitative analysis of damaged mitochondria calculated as percentage of total. (f) Cytochrome $c$ oxidase activity assayed in TA muscles. Data in (d) and (e) are shown as mean \pm SEM; ${ }^{*} p<0.05$, as evaluated by two-tailed unpaired Student's $t$ test for the $95 \%$ confidence intervals. Data in (f) are shown as mean $\pm \mathrm{SD} ;{ }^{*} p<0.05$, as evaluated by one-way ANOVA followed by Tukey's post hoc test. $n=$ number of fibers analyzed (in panels (d) and (e)) and number of mice (in panel (f)).

higher (32\%) compared to that generated in WT. To demonstrate that this $\mathrm{P}_{\mathrm{i}}$ generation was specifically dependent on the activity of SERCA, the same microsomes were treated with thapsigargin (TG, $100 \mathrm{nM})$, a noncompetitive inhibitor of SERCA [45]: after TG treatment, all samples exhibited a significant decay to $\sim 1.0 \mathrm{nmol} \mathrm{P}_{\mathrm{i}} \cdot \mathrm{mg}$ protein ${ }^{-1} \cdot \mathrm{min}^{-1}$, supporting the view of a different rate of SERCA activity in WT versus CASQ1-null fibers (Figure 6(a)). Though, SERCA activity was not reduced by aerobic training in CASQ1-null muscle. However, as increased levels of cytosolic $\mathrm{Ca}^{2+}$ may also result in an enhanced activation of proteolysis pathways [46], we also measured the total calpain activity, one of the most important nonlysosomal classes of proteases in skeletal muscle fibers, which is activated by chronic high $\mathrm{Ca}^{2+}$ levels $[46,65]$. In this case, calpain activity, measured in total homogenates of gastrocnemius muscles, that was 2.7-fold higher in untrained CASQ1-null than WT specimens, was significantly lowered in trained CASQ1-null samples (Figure 6(b)).

3.6. Oxidative Stress Was Reduced by Aerobic Training in Muscles of CASQ1-Null Mice. Oxidative stress has been shown to be elevated in CASQ1-null muscles [23]. To determine if aerobic exercise improved the capabilities of skeletal muscle to reduce oxidative damage, we evaluated (i) levels of carbonyl proteins (carbonyl protein content is an important biomarker of oxidative modification of proteins [53, 54]) and (ii) diene conjugates in total homogenates of TA muscle and in SR-and-mitochondria membranes of gastrocnemius muscles (diene conjugates are a by-product of lipid peroxidation chain, which is an indicator of structural oxidative modification to membranes [55]). The results obtained from these experiments revealed that (a) total carbonyl protein content was abnormally elevated in total muscle homogenates of untrained CASQ1-null compared to that of WT mice, while lowered of about 39\% in muscles of trained CASQ1-null mice (Figure 7(a)); (b) levels of diene conjugates were significantly increased either in total homogenates or in isolated mitochondria and SR membranes obtained from untrained CASQ1-null compared to WT muscles but reduced of about $40 \%$ in all three preparations obtained from trained CASQ1-null muscles (Figures 7(b)-7(d)). 


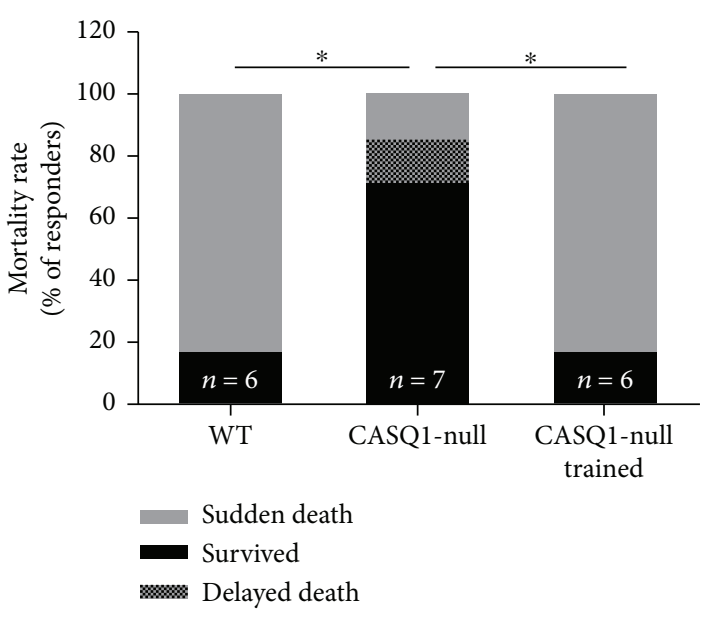

(a)

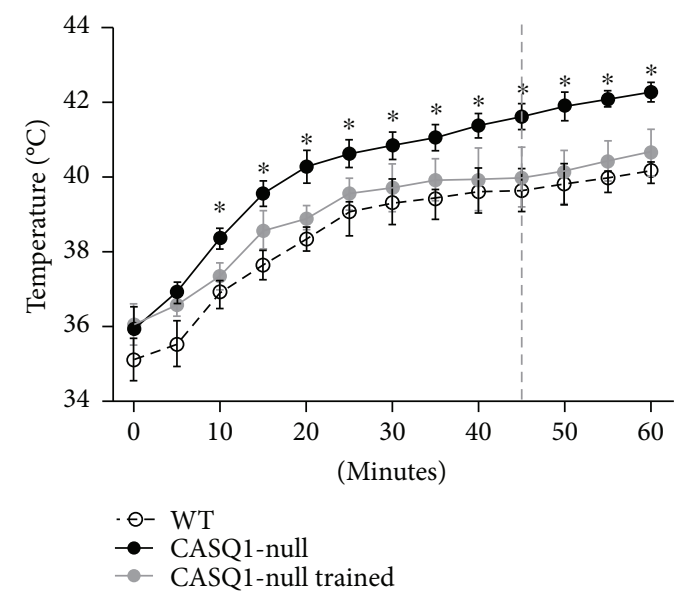

(c)

\begin{tabular}{lccc}
\hline Responders & WT & CASQ1-null & $\begin{array}{c}\text { CASQ1-null } \\
\text { trained }\end{array}$ \\
\hline Total tested & 6 & 7 & 6 \\
Survived & 5 & 1 & 5 \\
Sudden death & 1 & 5 & 1 \\
Delayed death & 0 & 1 & 0 \\
Survived (\%) & 83.3 & 16.7 & 83.3 \\
\hline & & &
\end{tabular}

(b)

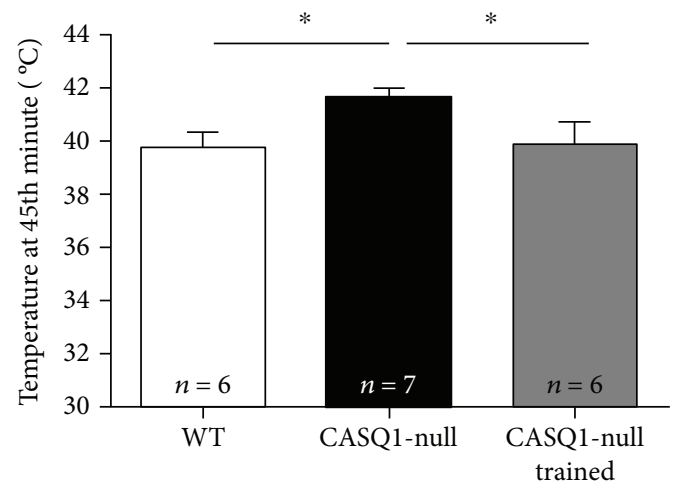

(d)

FIGURE 4: Mortality rate and measurements of core temperature in mice exposed to heat stress. (a) Incidence of sudden and delayed deaths (i.e., within $24 \mathrm{~h}$ after challenge) following exposure to the heat stress protocol $\left(41^{\circ} \mathrm{C}\right.$ for $\left.1 \mathrm{~h}\right) ;{ }^{*} p<0.05$, as evaluated by two-tailed Fisher's exact test. (b) Table showing (i) the number of mice tested during the heat challenge and (ii) the experimental outcome. (c) Increase in absolute core temperature, recorded every 5 minutes during exposure to the heat stress protocol: dashed vertical line represents the mean time-to-onset of lethal crises in CASQ1-null mice; ${ }^{*} p<0.05$, trained CASQ1-null versus both WT and trained CASQ1-null mice, as evaluated by two-way ANOVA followed by Bonferroni's post hoc test. (d) Average core temperature in mice at 45th minute of the heat stress protocol (dashed line in panel (c)). Data in (c) and (d) are given as mean $\pm \mathrm{SD} ;{ }^{*} p<0.05$, as evaluated by one-way ANOVA followed by Tukey's post hoc test. $n=$ number of mice (in panel (d)).

\section{Discussion}

In the last ten years, compelling evidence has been collected in animal models to demonstrate that EHS shares common molecular mechanisms with classic MH susceptibility, the reaction caused by exposure to halogenated anesthetics. Indeed, we and others have shown that knock-in mice carrying mutations in RYR1 linked to $\mathrm{MH}$ in humans (RYR $1^{\mathrm{Y} 522 \mathrm{~S} /}$ WT mice) and CASQ1-null mice trigger lethal crises when exposed to anesthetics, heat, and also physical exertion [16$18,21]$. The molecular events leading to rhabdomyolysis of skeletal fibers during hyperthermic crises in both mouse models involve $\mathrm{Ca}^{2+}$ leak from RyR1 and excessive production of ROS/RNS, which then feeds a feedforward cycle that promotes additional SR $\mathrm{Ca}^{2+}$ release [24]. We demonstrated that this cycle can be interrupted by administration of antioxidants ( $N$-acetylcysteine and trolox) [23, 24]. Here, we tested if aerobic training (Figure 1) can break the vicious cycle triggered by overproduction of ROS/RNS by boosting endogenous antioxidant defenses and, hence, prevent heatstrokes in CASQ1-null mice exposed to high environmental temperatures.

4.1. Main Findings of the Study. Our results show that aerobic training (a) protects mice from hyperthermic episodes, lowering both the increase in core temperature in vivo and the responsiveness of intact EDL muscles during IVCT (Figures 4 and 5), and (b) reduces oxidative stress, hence reducing mitochondrial damage (Figures 3, 6, and 7). Additionally, we also show that aerobic training had improved in vivo muscle performance, as shown by higher grip strength and maximal speed reached in the 


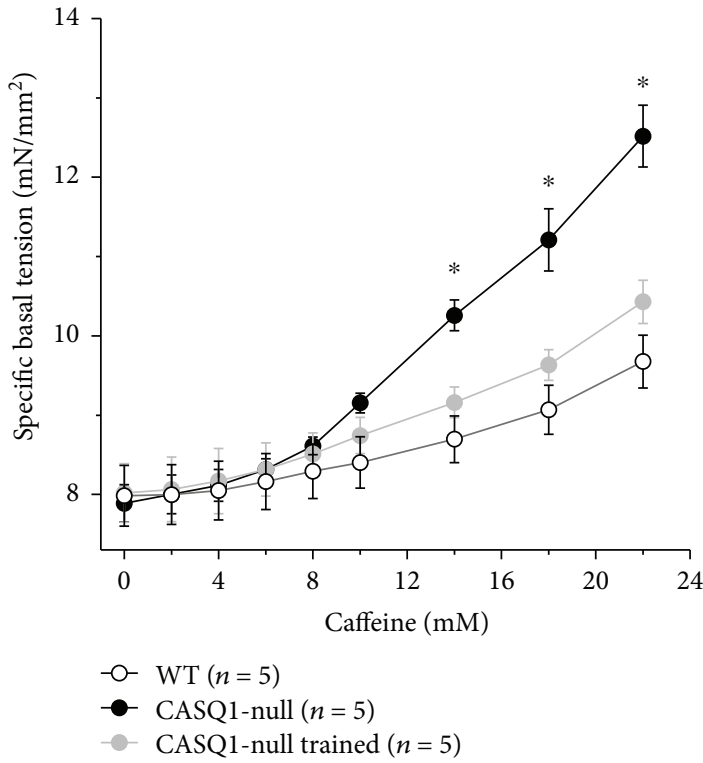

(a)

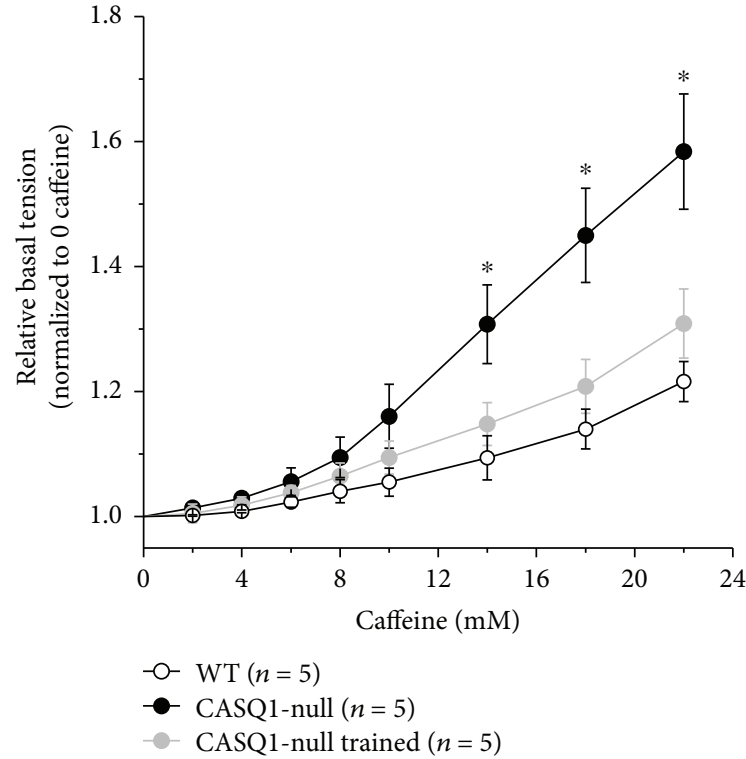

(b)

FIGURE 5: Caffeine dependence of basal tension in isolated EDL muscles during IVCT. (a) Specific basal tension of intact EDL muscles, recorded during exposure to increasing concentrations of caffeine. (b) Relative basal tension normalized to control conditions (no caffeine), during exposure to increasing concentrations of caffeine (same EDL muscles shown in panel (a)). Data are given as means \pm SEM; ${ }^{*} p<0.05$, as evaluated by ANOVA repeated measures, followed by Tukey's post hoc test for the pairwise comparisons. $n=$ number of mice tested.

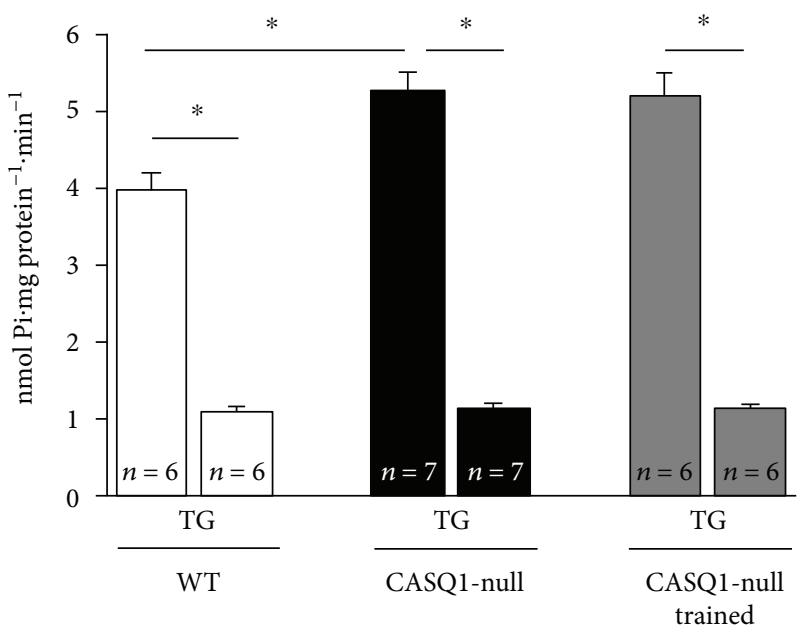

(a)

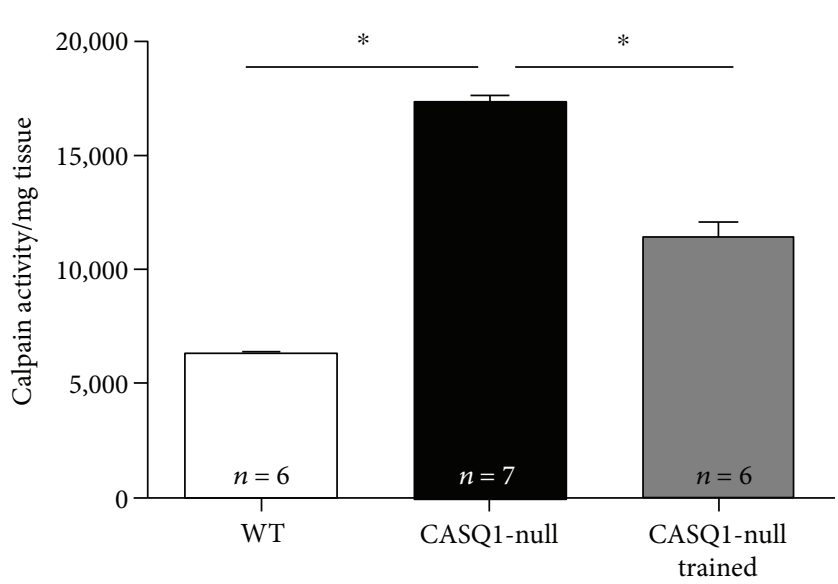

(b)

FIGURE 6: Measurements of SERCA and calpain activities. (a) SERCA activity assayed in microsomes isolated from gastrocnemius muscles in the absence and presence of $100 \mathrm{nM}$ of thapsigargin (TG). (b) Calpain activity assayed in gastrocnemius muscles total homogenates. Data are given as mean $\pm \mathrm{SD} ;{ }^{*} p<0.05$, as evaluated by one-way ANOVA followed by Tukey's post hoc test. $n=$ number of mice.

incremental test and by the reduced lactate accumulation in the bloodstream during the constant load test (Table 1 and Figure 2). These main points are discussed below in the same order.

4.1.1. Protection from Lethal EHS Episodes. The training program in CASQ1-null mice resulted in a striking protection from heat-induced lethal episodes, with the survival rate raising from $17 \%$ in untrained to $83 \%$ in trained CASQ1-null mice (Figure 4). The protective effect of aerobic training is likely the direct result of (i) a reduced rise in core temperature (i.e., hyperthermia) in trained versus untrained CASQ1-null animals (Figure 4) and (ii) a normalized IVCT (Figure 5), which is an indirect, but quite reliable, measurement of $\mathrm{Ca}^{2+}$ handling, as muscle tension directly correlates with intracellular $\mathrm{Ca}^{2+}$ concentration. The fact that intracellular $\mathrm{Ca}^{2+}$ levels are slightly elevated in CASQ1-null mice has been demonstrated and discussed in depth in several 


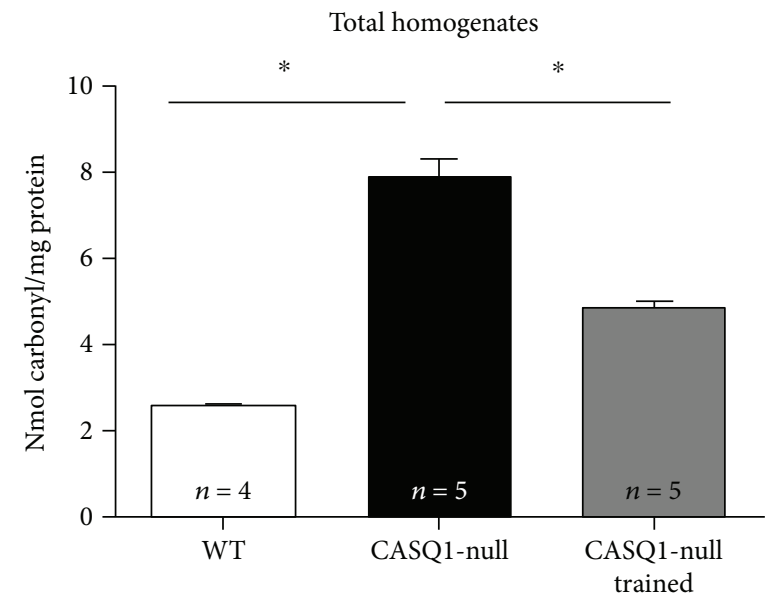

(a)

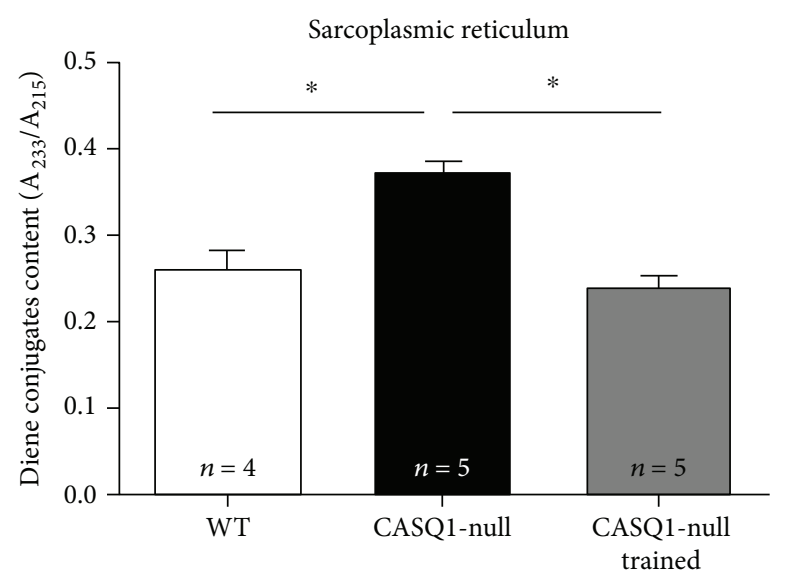

(c)

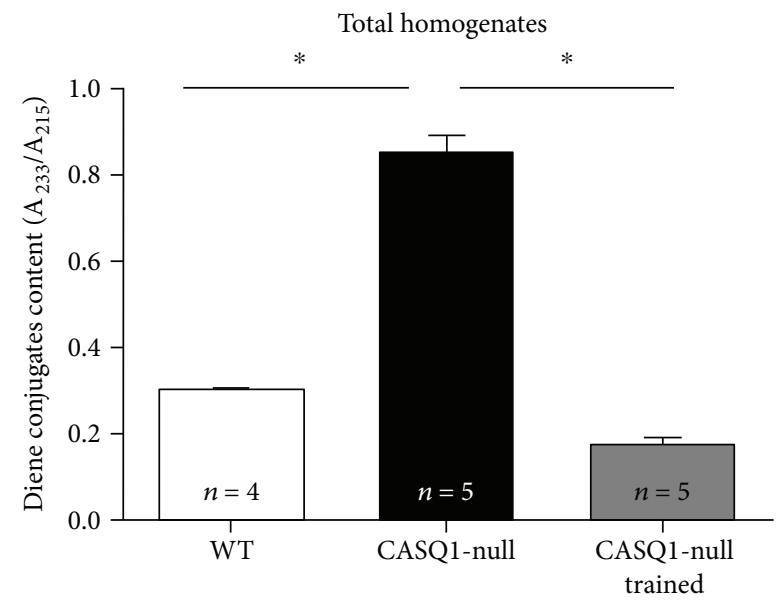

(b)

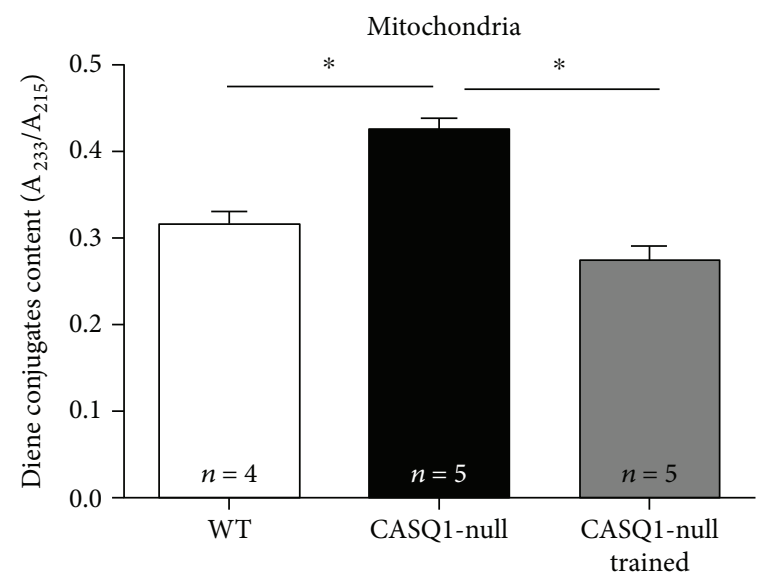

(d)

Figure 7: Oxidative modifications in proteins and membranes. Protein oxidation levels assayed by carbonyl protein content (a) and lipid peroxidation levels assayed by diene conjugate levels (b) in total homogenates from TA muscles. (c, d) Oxidative modifications assayed by diene conjugate levels in SR microsomes and in mitochondria isolated from gastrocnemius muscles. Data are given as mean \pm SD; ${ }^{*} p<$ 0.05 , as evaluated by one-way ANOVA followed by Tukey's post hoc test. $n=$ number of mice.

previous publications $[18,21,23,61]$. The elevated intracellular $\mathrm{Ca}^{2+}$ levels in untrained CASQ1-null muscles are here underlined both by IVCT (see above) and by increased SERCA and calpain activities (Figure 6). Indeed, both SERCA and calpain have been demonstrated to have their activities increased under conditions in which myoplasmic $\mathrm{Ca}^{2+}$ concentration is elevated $[46,47,66]$. Although aerobic training did not reduce the activity of SERCA, it did lower that of calpain, an effect that could contribute to several aspects presented in this work (see below).

4.1.2. Protection from Oxidative Stress and Damage. Aerobic training resulted in a striking protection from heat-induced lethal episodes in CASQ1-null mice (Figure 4). Noticeable, a similar protection against EHS was also achieved treating CASQ1-null animals with antioxidants [23], or with estrogens [67], the primary female sex steroid hormones which have been shown to exhibit antioxidant properties [68-71]. Here we show that aerobic training, similarly to antioxidants and estrogens, reduces oxidative stress in CASQ1-null mice.
Specifically, we demonstrated that protein carbonylation and diene conjugate formation, well-established markers of oxidative damage to proteins [53] and of lipid peroxidation [55], are greatly reduced in CASQ1-null mice subjected to aerobic training (Figure 7). This effect is possibly achieved, thanks to the increased endogenous antioxidant protection, as lipid peroxidation is strongly influenced by endogenous antioxidant defenses $[55,56]$. The fact that aerobic training reduces oxidative stress is not surprising: the training protocol used in the present study (Figure 1) was indeed demonstrated to increase aerobic capacity and to counteract protein and lipid oxidative modifications in skeletal muscles of heart failure-bearing animals [34]. In addition, many investigators have reported that exercise training boosts antioxidant defenses [33, 34, 72-74] while decreasing lipid peroxidation [29] and oxidative modifications to proteins and RNA [55].

4.1.3. Adaptations of CASQ1-Null Mice to Exercise. Muscle function and lactate production were evaluated in all three 
groups of mice (Table 1) and allowed to determine differences caused by adaptation of muscle to lack of CASQ1 (control CASQ1-null versus WT) and to training (control versus trained CASQ1-null). While grip strength test indicated that control CASQ1-null mice are weaker than agematched WT (Table 1), a result in accordance with data previously published $[23,61]$, the maximal speed reached during the incremental test was greater in knockout animals. While surprising, this finding is possibly explained by the much greater content of mitochondria in muscle fibers from CASQ1-null mice (Figure 3 and [27]) and by the higher capability of knockout animals to remove lactate from their bloodstream (Figure 2). On the other hand, not surprising was the fact that aerobic training in CASQ1-null mice improved both the grip strength and the performance in the incremental test (Table 1). The improved capabilities of CASQ1-null following training may be the direct result of (i) the reduced blood lactate accumulation (Figure 2) and of (ii) the improved mitochondrial structure and function (Figure 3).

4.2. Altered Mitochondria Are a Potential Source of Excessive Oxidative Stress. Generation of free radicals inside the cells may arise from multiple sources, including mitochondria [75]. The enzyme cytochrome $c$ oxidase is a transmembrane protein found in the inner mitochondrial membrane, crucial for ATP synthesis [52], a process that can produce superoxide anion $\left(\mathrm{O}_{2}{ }^{\bullet-}\right)$ [76]. Production of oxidative species may increase once mitochondria are damaged [76, 77]. Indeed, in untrained CASQ1-null muscle fibers, mitochondria are more frequently damaged than in WT while activity of cytochrome $c$ is reduced and oxidative stress is elevated (Figures 3 and 7). In previous publications, we already showed elevated mitochondrial damage and increased levels of superoxide dismutase 1 and 2, respectively, the cytosolic and the mitochondrial isoforms $[23,67]$. Present data also show that aerobic training in CASQ1-null mice reduces mitochondrial damage while increasing cytochrome $c$ oxidase activity, likely as the consequence of reduced calpain activity (Figure 6) and oxidative stress (Figure 7). In turn, improved mitochondrial structure could also contribute to the improved muscle performance (Table 1).

4.3. Closing Remarks. In latest years, global warming has become reason of health concern $[78,79]$ because of (a) the increased frequency and severity of unusual heat waves (i.e., period of abnormally high temperatures and humidity) [78] and (b) a dramatic rise in the mortality rate due to heatrelated illnesses during these heat waves $[80,81]$. The impact of heat waves is especially severe in urban areas and well documented in literature (more than 1000 scientific reports). Surprisingly, these reports indicate that $95 \%$ of human deaths due to natural hazards are caused by hot and humid weather $[82,83]$. The 2003 heat wave in France, one of the better described in literature, was accompanied by an excess mortality of exceptional magnitude: 14,947 excess deaths for the period of August 4-18. Interestingly, mortality rate of the population returned to its normal level starting on August 19 [84]. Also striking was the rate of mortality in the 1995 heat wave in Chicago [81]. A recent report indicates that the effects of high temperatures over consecutive days on human health are quite similar to those caused by single unusually hot days [85]. Even if several factors may contribute to the death caused by high environmental temperatures (age, preexisting disease, urban residence, isolation, poverty, and air pollution), the most common cause of death attributable to heat is dehydration, heat cramps and exhaustion, and hyperthermia, that is, in one word EHS [85]. EHS is life-threatening mainly because skeletal muscle represents a high percentage of the human body mass, and even rhabdomyolysis of a small percentage of fibers will cause a significant modification of the blood parameters, which in turn may challenge heart and kidney functions [1]. Understanding the molecular mechanisms underlying EHS, and dissect which molecular pathways must be interrupted to prevent/revert crises, is crucial. Also urgent is the development of (a) drugs to be used in emergency situations and (b) life habits that may prevent the triggering of EHS in hot weather. Here we have shown that in CASQ1-null mice, which are susceptible to both exertional and environmental heatstroke $[18,21$, 23], aerobic training significantly reduced the mortality rate during exposure to heat by lowering oxidative stress. This knowledge may help in the future to develop guidelines for those populations on earth that are frequently exposed to high environmental temperatures, hence to the risk of EHS.

$\begin{array}{ll}\text { Abbreviations } \\ \text { CASQ1: } & \text { Calsequestrin type-1 } \\ \text { CASQ1-null: } & \text { CASQ1 knockout mice } \\ \text { CK: } & \text { Creatine kinase } \\ \text { EDL: } & \text { Extensor digitorum longus } \\ \text { EHS: } & \text { Exertional/environmental heatstroke } \\ \text { EM: } & \text { Electron microscopy } \\ \text { IVCT: } & \text { In vitro contracture test } \\ \text { MH: } & \text { Malignant hyperthermia } \\ \text { RyR1: } & \text { Ryanodine receptor type-1 } \\ \text { SERCA: } & \text { Sarcoplasmic/endoplasmic reticulum } \mathrm{Ca}^{2+} \\ & \text { ATPase } \\ \text { SR: } & \text { Sarcoplasmic reticulum } \\ \text { TA: } & \text { Tibialis anterior } \\ \text { WT: } & \text { Wild type. }\end{array}$

\section{Conflicts of Interest}

The authors declare that they have no conflicts of interest.

\section{Authors' Contributions}

Feliciano Protasi directed the study. Flávia Alessandra Guarnier conceived and designed the experimental protocol of Figure 1. Flávia Alessandra Guarnier, Antonio Michelucci, Matteo Serano, Laura Pietrangelo, Claudia Pecorai, and Simona Boncompagni performed the experimental work and data analysis. Flávia Alessandra Guarnier performed (a) training, blood lactate collection, and measurements 
(Figure 2); (b) in vivo experiments of mortality rate and internal temperature measurements (Figure 4); (c) $\mathrm{Ca}^{2+}$ ATPase and calpain activities (Figure 6); and (d) measurements of oxidative stress (Figure 7). Matteo Serano contributed to training and blood collection. Simona Boncompagni, Laura Pietrangelo, and Claudia Pecorai performed the EM analysis (Figure 3). Antonio Michelucci performed IVCT experiments in isolated EDL muscles (Figure 5). Finally, Flávia Alessandra Guarnier, Antonio Michelucci, Simona Boncompagni, and Feliciano Protasi wrote and edited the manuscript.

\section{Acknowledgments}

This study was supported by the following grants: (a) Italian Telethon ONLUS Foundation (Rome, Italy) no. GGP13213 to Feliciano Protasi; (b) Brazilian Ciências sem Fronteiras no. 233898/2014-1 to Flávia Alessandra Guarnier; (c) National Institute of Health (Bethesda, MD, USA) no. AR059646-06 (subcontract to Feliciano Protasi); (d) Italian Ministry of Education, University and Research no. PRIN 2015ZZR4W3 to Feliciano Protasi; and (e) Italian Ministry of Health (Rome, Italy) no. GR-201102352681 to Simona Boncompagni.

\section{References}

[1] A. Bouchama and J. P. Knochel, "Heat stroke," The New England Journal of Medicine, vol. 346, no. 25, pp. 1978-1988, 2002.

[2] M. A. Denborough, J. F. Forster, R. R. Lovell, P. A. Maplestone, and J. D. Villiers, "Anaesthetic deaths in a family," British Journal of Anaesthesiology, vol. 34, no. 6, pp. 395-396, 1962.

[3] H. Rosenberg, M. Davis, D. James, N. Pollock, and K. Stowell, "Malignant hyperthermia," Orphanet Journal of Rare Diseases, vol. 2, no. 1, pp. 21-34, 2007.

[4] P. M. Hopkins, F. R. Ellis, and P. J. Halsall, "Evidence for related myopathies in exertional heat stroke and malignant hyperthermia," The Lancet, vol. 338, no. 8781, pp. 14911492, 1991.

[5] F. Lehmann-Horn, W. Klinger, and K. Jurkat-Rott, "Nonanesthetic malignant hyperthermia," Anesthesiology, vol. 115, no. 5, pp. 915-917, 2011.

[6] T. Pamukcoglu, "Sudden death due to malignant hyperthermia," The American Journal of Forensic Medicine and Pathology, vol. 9, no. 2, pp. 161-162, 1998.

[7] R. Robinson, D. Carpenter, M. A. Shaw, J. Halsall, and P. Hopkins, "Mutations in RYR1 in malignant hyperthermia and central core disease," Human Mutations, vol. 27, no. 10, pp. 977-989, 2006.

[8] C. Franzini-Armstrong and F. Protasi, "Ryanodine receptors of striated muscles: a complex channel capable of multiple interactions," Physiological Reviews, vol. 77, no. 3, pp. 699729, 1997.

[9] M. F. Schneider, "Control of calcium release in functioning skeletal muscle fibers," Annual Review of Physiology, vol. 56, no. 1, pp. 463-484, 1994.

[10] M. Davis, R. Brown, A. Dickson et al., "Malignant hyperthermia associated with exercise-induced rhabdomyolysis or congenital abnormalities and a novel RYR1 mutation in
New Zealand and Australian pedigrees," British Journal of Anaesthesiology, vol. 88, no. 4, pp. 508-515, 2002.

[11] J. R. Tobin, D. Jason, V. R. Challa, T. E. Nelson, and N. Sambuughin, "Malignant hyperthermia and apparent heat stroke," JAMA, vol. 286, no. 2, pp. 168-169, 2001.

[12] J. F. Capacchione, N. Sambuughin, S. Bina, L. P. Mulligan, T. D. Lawson, and S. M. Muldoon, "Exertional rhabdomyolysis and malignant hyperthermia in a patient with ryanodine receptor type 1 gene, L-type calcium channel $\alpha$ - 1 subunit gene, and calsequestrin-1 gene polymorphisms," Anesthesiology, vol. 112, no. 1, pp. 239-244, 2010.

[13] L. Groom, S. M. Muldoon, Z. Z. Tang et al., "Identical de novo mutation in the type 1 ryanodine receptor gene associated with fatal, stress-induced malignant hyperthermia in two unrelated families," Anesthesiology, vol. 115, no. 5, pp. 938-945, 2011.

[14] T. E. Nelson, E. W. Jones, J. H. Venable, and D. D. Kerr, "Malignant hyperthermia of Poland China swine: studies of a myogenic etiology," Anesthesiology, vol. 36, no. 1, pp. 52-56, 1972.

[15] E. W. Jones, T. E. Nelson, I. L. Anderson, D. D. Kerr, and T. K. Burnap, "Malignant hyperthermia of swine," Anesthesiology, vol. 36, no. 1, pp. 42-51, 1972.

[16] M. G. Chelu, S. A. Goonasekera, W. J. Durham et al., "Heatand anesthesia-induced malignant hyperthermia in an RyR1 knock-in mouse," The FASEB Journal, vol. 20, no. 2, pp. 329330, 2006.

[17] T. Yang, J. Riehl, E. Esteve et al., "Pharmacologic and functional characterization of malignant hyperthermia in the R163C RyR1 knock-in mouse," Anesthesiology, vol. 105, no. 6, pp. 1164-1175, 2006.

[18] A. Michelucci, C. Paolini, S. Boncompagni, M. Canato, C. Reggiani, and F. Protasi, "Strenuous exercise triggers a lifethreatening response in mice susceptible to malignant hyperthermia," The FASEB Journal, vol. 31, no. 8, pp. 3649-3662, 2017.

[19] D. H. MacLennan and P. T. Wong, "Isolation of a calciumsequestering protein from sarcoplasmic reticulum," Proceedings of the National Academy of Sciences of the United States of America, vol. 68, no. 6, pp. 1231-1235, 1971.

[20] N. A. Beard, M. M. Sakowska, A. F. Dulhunty, and D. R. Laver, "Calsequestrin is an inhibitor of skeletal muscle ryanodine receptor calcium release channels," Biophyscal Journal, vol. 82, no. 1, pp. 310-320, 2002.

[21] M. Dainese, M. Quarta, A. D. Lyfenko et al., "Anestheticand heat-induced sudden death in calsequestrin-1knockout mice," The FASEB Journal, vol. 23, no. 6, pp. 1710-1720, 2009.

[22] F. Protasi, C. Paolini, and M. Dainese, "Calsequestrin-1: a new candidate gene for malignant hyperthermia and exertional/ environmental heat stroke," The Journal of Physiology, vol. 587, no. 13, pp. 3095-3100, 2009.

[23] A. Michelucci, C. Paolini, M. Canato et al., "Antioxidants protect calsequestrin-1 knockout mice from halothane- and heat-induced sudden death," Anesthesiology, vol. 123, no. 3, pp. 603-617, 2015.

[24] W. J. Durham, P. Aracena-Parks, C. Long et al., "RyR1 Snitrosylation underlies environmental heat stroke and sudden death in Y522S RyR1 knockin mice," Cell, vol. 133, no. 1, pp. 53-65, 2008.

[25] A. Carsana, "Exercise-induced rhabdomyolysis and stressinduced malignant hyperthermia events, association with 
malignant hyperthermia susceptibility, and RYR1 gene sequence variations," The Scientific World Journal, vol. 2013, Article ID 531465, 6 pages, 2013.

[26] P. Aracena-Parks, S. A. Goonasekera, C. P. Gilman, R. T. Dirksen, C. Hidalgo, and S. L. Hamilton, "Identification of cysteines involved in S-nitrosylation, S-glutathionylation, and oxidation to disulfides in ryanodine receptor type 1," Journal of Biological Chemistry, vol. 281, no. 52, pp. 40354-40368, 2006.

[27] C. Paolini, M. Quarta, A. Nori et al., "Reorganized stores and impaired calcium handling in skeletal muscle of mice lacking calsequestrin-1," The Journal of Physiology, vol. 583, no. 2, pp. 767-784, 2007.

[28] F. Protasi, C. Paolini, M. Canato, C. Reggiani, and M. Quarta, "Lessons from calsequestrin-1 ablation in vivo: much more than a $\mathrm{Ca}^{2+}$ buffer after all," Journal of Muscle Research and Cell Motility, vol. 32, no. 4-5, pp. 257-270, 2011.

[29] H. M. Alessio and A. H. Goldfarb, "Lipid peroxidation and scavenger enzymes during exercise: adaptive response to training," Journal of Applied Physiology, vol. 64, no. 4, pp. 13331336, 1988.

[30] K. Davies, A. Quintanilha, G. Brooks, and L. Packer, "Free radicals and tissue damage produced by exercise," Biochemical and Biophysical Research Communications, vol. 107, no. 4, pp. 1198-1205, 1982.

[31] L. L. Ji, F. W. Stratman, and H. A. Lardy, "Antioxidant enzyme systems in rat liver and skeletal muscle: influences of selenium deficiency, chronic training, and acute exercise," Archives of Biochemistry and Biophysics, vol. 263, no. 1, pp. 150-160, 1988.

[32] D. Criswell, S. Powers, S. Dodd et al., "High intensity traininginduced changes in skeletal muscle antioxidant enzyme activity," Medicine \& Science in Sports \& Exercise, vol. 25, no. 10, pp. 1135-1140, 1993.

[33] J. C. Ferreira, A. V. Bacurau, C. R. Bueno Jr. et al., "Aerobic exercise training improves $\mathrm{Ca}^{2+}$ handling and redox status of skeletal muscle in mice," Experimental Biology and Medicine, vol. 235, no. 4, pp. 497-505, 2010.

[34] T. F. Cunha, A. V. Bacurau, J. B. Moreira et al., "Exercise training prevents oxidative stress and ubiquitin-proteasome system overactivity and reverse skeletal muscle atrophy in heart failure," PLoS One, vol. 7, no. 8, p. e41701, 2012.

[35] L. B. Gladden and M. C. Hogan, "Lactic acid accumulation is an advantage/disadvantage during muscle activity," Journal of Applied Physiology, vol. 100, no. 6, pp. 2100-2101, 2006.

[36] A. M. Connolly, R. M. Keeling, S. Mehta, A. Pestronk, and J. R. Sanes, "Three mouse models of muscular dystrophy: the natural history of strength and fatigue in dystrophin-, dystrophin/ utrophin-, and laminin $\alpha 2$-deficient mice," Neuromuscular Disorders, vol. 11, no. 8, pp. 703-712, 2001.

[37] M. Munkvik, P. K. Lunde, and O. M. Sejersted, "Causes of fatigue in slow-twitch rat skeletal muscle during dynamic activity," American Journal of Physiology Regulatory, Integrative and Comparative Physiology, vol. 297, no. 3, pp. R900R910, 2009.

[38] F. A. Guarnier, A. L. Cecchini, A. A. Suzukawa et al., "Time course of skeletal muscle loss and oxidative stress in rats with Walker 256 solid tumor," Muscle \& Nerve, vol. 42, no. 6, pp. 950-958, 2010.

[39] E. Babušíková, P. Kaplán, J. Lehotský, M. Jesenák, and D. Dobrota, "Oxidative modification of rat cardiac mitochondrial membranes and myofibrils by hydroxyl radicals," General Physiology and Biophysics, vol. 23, no. 3, pp. 327-335, 2004.

[40] R. Cecchini, O. I. Aruoma, and B. Halliwell, "The action of hydrogen peroxide on the formation of thiobarbituric acidreactive material from microsomes, liposomes or from DNA damaged by bleomycin or phenanthroline. Artefacts in the thiobarbituric acid test," Free Radical Research Communications, vol. 10, no. 4-5, pp. 245-258, 1990.

[41] B. A. Eason, Purification and Properties of Skeletal Muscle Microsomes, Retrospective Theses and Dissertations Iowa State University Digital Repository, Ames, IA, USA, 1969.

[42] M. M. Bradford, "A rapid and sensitive method for the quantitation of microgram quantities of protein utilizing the principle of protein-dye binding," Analytical Biochemistry, vol. 72, no. 1-2, pp. 248-254, 1976.

[43] H. H. Taussky and E. Shorr, "A microcolorimetric method for the determination of inorganic phosphorus," Journal of Biological Chemistry, vol. 202, no. 2, pp. 675-685, 1953.

[44] D. C. Mc Mullen, W. S. Kean, A. Verma, J. T. Cole, and W. D. Watson, "A microplate technique to simultaneously assay calcium accumulation in endoplasmic reticulum and SERCA release of inorganic phosphate," Biological Procedures Online, vol. 14, no. 1, pp. 4-11, 2012.

[45] J. Lytton, M. Westlin, and M. R. Hanley, "Thapsigargin inhibits the sarcoplasmic or endoplasmic reticulum CaATPase family of calcium pumps," Journal of Biological Chemistry, vol. 266, no. 26, pp. 17067-17071, 1991.

[46] P. Costelli, P. Reffo, F. Penna, R. Autelli, G. Bonelli, and F. M. Baccino, "Ca ${ }^{2+}$-dependent proteolysis in muscle wasting," The International Journal of Biochemistry \& Cell Biology, vol. 37, no. 10, pp. 2134-2146, 2005.

[47] D. E. Goll, V. F. Thompson, H. Li, W. Wei, and J. Cong, "The calpain system," Physiological Reviews, vol. 83, no. 3, pp. 731801, 2003.

[48] F. H. Borges, P. C. Marinello, A. L. Cecchini, F. P. Blegniski, F. A. Guarnier, and R. Cecchini, "Oxidative and proteolytic profiles of the right and left heart in a model of cancerinduced cardiac cachexia," Pathophysiology, vol. 21, no. 4, pp. 257-265, 2017.

[49] L. Pietrangelo, A. D’Incecco, A. Ainbinder et al., “Age-dependent uncoupling of mitochondria from $\mathrm{Ca}^{2+}$ release units in skeletal muscle," Oncotarget, vol. 6, no. 34, pp. 35358-35371, 2015.

[50] A. V. Loud, "A method for the quantitative estimation of cytoplasmic structures," Journal of Cell Biology, vol. 15, no. 3, pp. 481-487, 1962.

[51] B. A. Mobley and B. R. Eisenberg, "Sizes of components in frog skeletal muscle measured by methods of stereology," The Journal of General Physiology, vol. 66, no. 1, pp. 31-45, 1975.

[52] M. V. Gilmour, M. R. Lemberg, and B. Chance, "Cytochrome oxidase and its derivatives. IX. Spectrophotometric studies on the rapid reaction of ferrous cytochrome $c$ oxidase with molecular oxygen under conditions of complete and partial oxygenation," Biochimica et Biophysica Acta (BBA) - Bioenergetics, vol. 172, no. 1, pp. 37-51, 1969.

[53] A. Z. Reznick and L. Packer, "Oxidative damage to proteins: spectrophotometric method for carbonyl assay," Methods in Enzymology, vol. 233, pp. 357-363, 1994.

[54] D. Weber, M. J. Davies, and T. Grune, "Determination of protein carbonyls in plasma, cell extracts, tissue homogenates, 
isolated proteins: focus on sample preparation and derivatization conditions," Redox Biology, vol. 5, pp. 367-380, 2015.

[55] B. Halliwell and J. M. C. Gutteridge, Free Radicals in Biology and Medicine, Oxford University Press Inc., New York, NY, USA, 4th edition, 2007.

[56] J. M. Brauhgler, L. A. Duncan, and R. L. Chase, "The involvement of iron in lipid peroxidation. Importance of ferric to ferrous ratios in initiation," Journal of Biological Chemistry, vol. 261, no. 22, pp. 10282-10289, 1986.

[57] R. A. Klein, "The detection of oxidation in liposome preparations," Biochimica et Biophysica Acta (BBA) - Lipids and Lipid Metabolism, vol. 210, no. 3, pp. 486-489, 1970.

[58] T. Yoshida, M. Chida, M. Ichioka, and Y. Suda, "Blood lactate parameters related to aerobic capacity and endurance performance," European Journal of Applied Physiology and Occupational Physiology, vol. 56, no. 1, pp. 7-11, 1987.

[59] J. C. Ferreira, N. P. Rolim, J. B. Bartholomeu, C. A. Gobatto, E. Kokubun, and P. C. Brum, "Maximal lactate steady state in running mice: effect of exercise training," Clinical and Experimental Pharmacology and Physiology, vol. 34, no. 8, pp. 760-765, 2007.

[60] A. E. R. Boncompagni, M. Micaroni, G. V. Beznoussenko, R. S. Polishchuk, R. T. Dirksen, and F. Protasi, "Mitochondria are linked to calcium stores in striated muscle by developmentally regulated tethering structures," Molecular Biology of the Cell, vol. 20, no. 3, pp. 1058-1067, 2009.

[61] C. Paolini, M. Quarta, L. Wei-LaPierre et al., "Oxidative stress, mitochondrial damage, and cores in muscle from calsequestrin-1 knockout mice," Skeletal Muscle, vol. 5, no. 1, pp. 10-17, 2015.

[62] European Malignant Hyperthermia Group, “A protocol for the investigation of malignant hyperpyrexia (MH) susceptibility. The European Malignant Hyperpyrexia Group," British Journal of Anaesthesiology, vol. 56, no. 11, pp. 12671269, 1984.

[63] M. G. Larach, "Standardization of the caffeine halothanemuscle contracture test," Anesthesia \& Analgesia, vol. 69, no. 4, pp. 511-515, 1989.

[64] A. R. Tupling, H. J. Green, B. D. Roy, S. Grant, and J. Ouyang, "Paradoxical effects of prior activity on human sarcoplasmic reticulum $\mathrm{Ca}^{2+}$-ATPase response to exercise," Journal of Applied Physiology, vol. 95, no. 1, pp. 138-144, 2003.

[65] D. E. Croall and G. N. DeMartino, "Calcium-activated neutral protease (calpain) system: structure, function, and regulation," Physiological Reviews, vol. 71, no. 3, pp. 813-847, 1991.

[66] J. C. Calderón, P. Bolaños, and C. Caputo, "The excitationcontraction coupling mechanism in skeletal muscle," Biophysical Reviews, vol. 6, no. 1, pp. 133-160, 2014.

[67] A. Michelucci, S. Boncompagni, M. Canato, C. Reggiani, and F. Protasi, "Estrogens protect calsequestrin-1 knockout mice from lethal hyperthermic episodes by reducing oxidative stress in muscle," Oxidative Medicine and Cellular Longevity, vol. 2017, Article ID 6936897, 15 pages, 2017.

[68] K. Sugioka, Y. Shimosegawa, and M. Nakano, "Estrogens as natural antioxidants of membrane phospholipid peroxidation," FEBS Letters, vol. 210, no. 1, pp. 37-39, 1987.

[69] A. D. Mooradian, "Antioxidant properties of steroids," The Journal of Steroid Biochemistry and Molecular Biology, vol. 45, no. 6, pp. 509-511, 1993.

[70] M. A. Gomez-Zubeldia, J. J. Arbues, G. Hinchado, A. G. Nogales, and J. C. Millán, "Influence of estrogen replacement therapy on plasma lipid peroxidation," Menopause, vol. 8, no. 4, pp. 274-280, 2001.

[71] C. Borras, J. Gambini, M. C. Gómez-Cabrera et al., “17 $\beta$-oestradiol up-regulates longevity-related, antioxidant enzyme expression via the ERK1 and $\mathrm{RK} 22^{\mathrm{MAPK}} / \mathrm{NF} \kappa \mathrm{B}$ cascade," Aging Cell, vol. 4, no. 3, pp. 113-118, 2005.

[72] R. R. Jenkins, "Exercise, oxidative stress and antioxidants: a review," International Journal of Sports and Nutrition, vol. 3, no. 4, pp. 356-375, 1993.

[73] A. T. Quintanilha, "Effects of physical exercise and/or vitamin E tissue oxidation metabolism," Biochemical Society Transactions, vol. 12, no. 3, pp. 403-404, 1984.

[74] A. Done and T. Traustadóttir, "Nrf2 mediates redox adaptations to exercise," Redox Biology, vol. 10, pp. 191-199, 2016.

[75] D. Munro and J. R. Treberg, "A radical shift in perspective: mitochondria as regulators of reactive oxygen species," Journal of Experimental Biology, vol. 220, no. 7, pp. 1170-1180, 2017.

[76] G. A. Loschen, A. Azzi, C. Richter, and L. Flohé, "Superoxide radicals as precursors of mitochondrial hydrogen peroxide," FEBS Letters, vol. 42, no. 1, pp. 68-72, 1974.

[77] C. Saporito-Magriñá, R. Musacco-Sebio, J. Acosta et al., "Copper(II) and iron(III) ions inhibit respiration and increase free radical-mediated phospholipid peroxidation in rat liver mitochondria: effect of antioxidants," Journal of Inorganic Biochemistry, vol. 172, pp. 94-99, 2017.

[78] J. T. Houghton, Y. Ding, D. J. Griggs et al., "Intergovernmental Panel on Climate Change," in IPCC Third Assessment Report, Cambridge University Press, Cambridge, NY, USA, 2001.

[79] R. Samu and J. M. Samet, "Relation between elevated ambient temperature and mortality: a review of the epidemiologic evidence," Epidemiologic Reviews, vol. 24, no. 2, pp. 190-202, 2002.

[80] D. J. Gaffen and R. J. Ross, "Increased summertime heat stress in the US," Nature, vol. 396, no. 6711, pp. 529-530, 1998.

[81] J. C. Semenza, C. H. Rubin, K. H. Falter et al., "Heat-related deaths during the July 1995 heat wave in Chicago," The New England Journal of Medicine, vol. 335, no. 2, pp. 84-90, 1996.

[82] C. Posey, "Heat wave," Weatherwise, vol. 33, no. 3, pp. 112 116,1980

[83] A. Blong, Centre Issues Paper No. 4, University College, London, London, 2005.

[84] M. Poumadère, C. Mays, S. Le Mer, and R. Blong, “The 2003 heat wave in France: dangerous climate change here and now," Risk Analysis, vol. 25, no. 6, pp. 1483-1494, 2005.

[85] T. P. Yeo, "Heat stroke: a comprehensive review," AACN Clinical Issues: Advanced Practice in Acute and Critical Care, vol. 15, no. 2, pp. 280-293, 2004. 


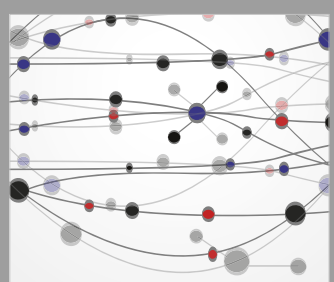

The Scientific World Journal
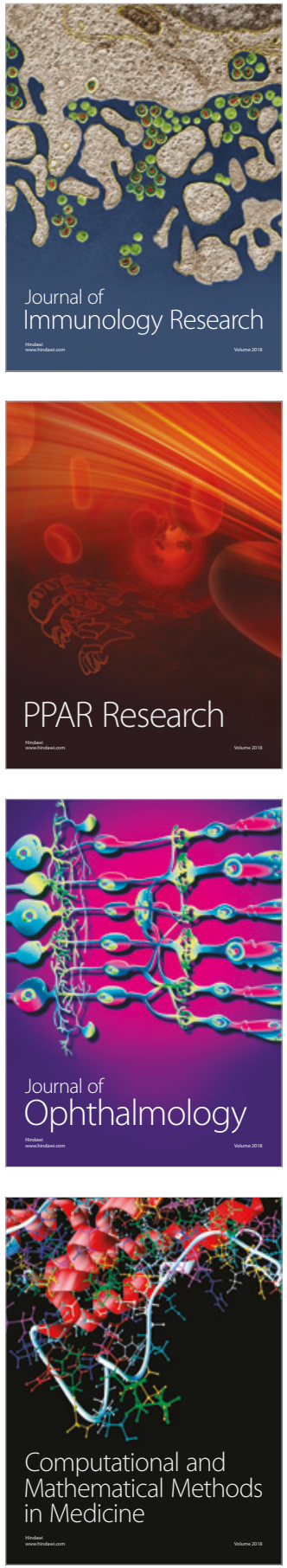

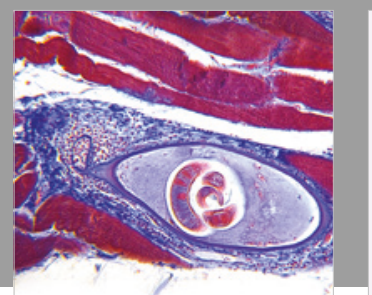

Gastroenterology Research and Practice

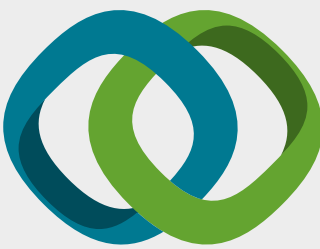

\section{Hindawi}

Submit your manuscripts at

www.hindawi.com
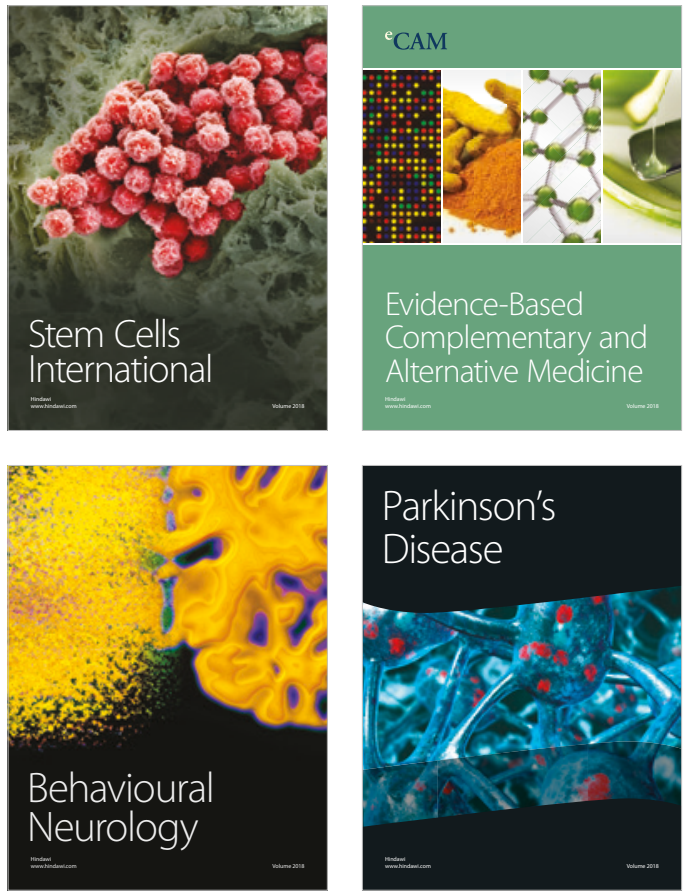

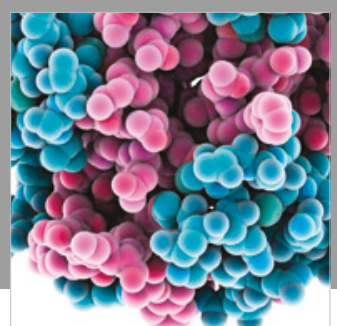

ournal of

Diabetes Research

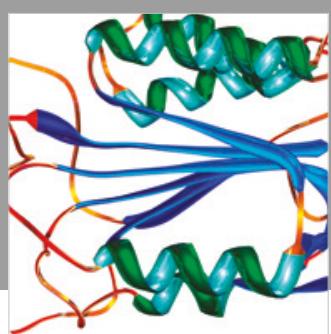

Disease Markers
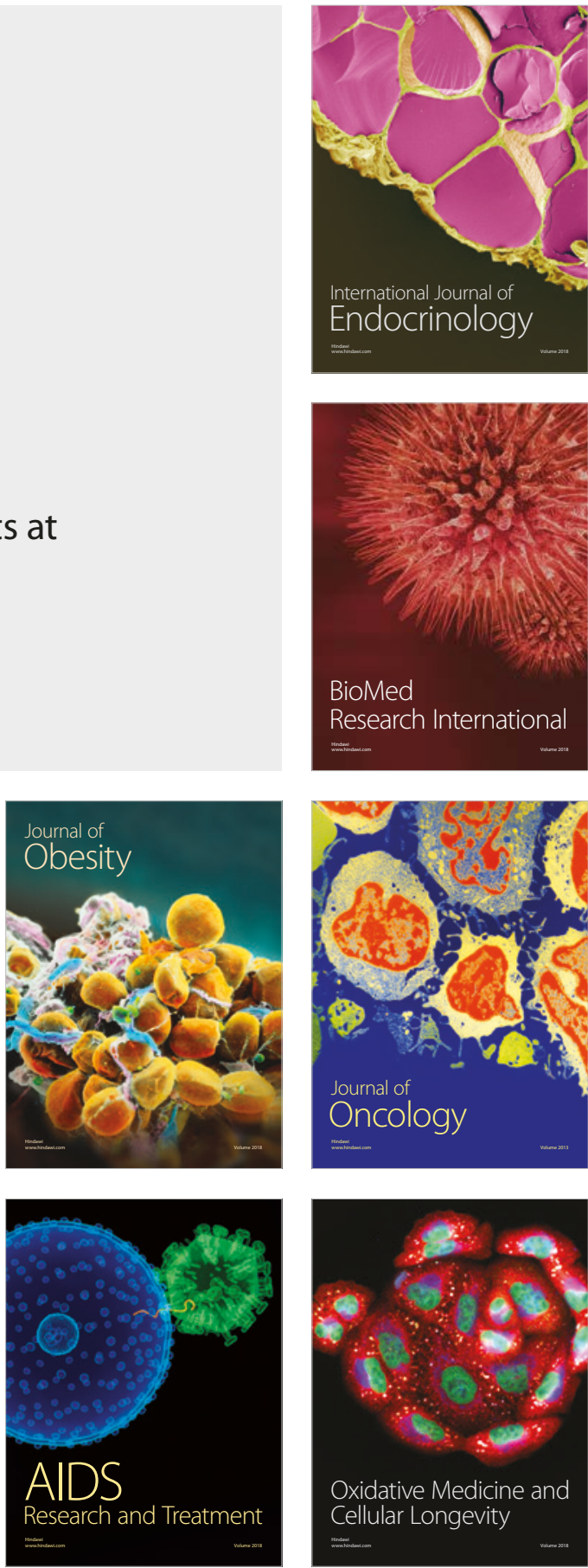